\title{
Raffinose Family Oligosaccharides: Friend or Foe for Human and Plant Health?
}

\author{
Dinakaran Elango ${ }^{1 *}$, Karthika Rajendran², Liza Van der Laan', Sheelamary Sebastiar ${ }^{3}$, \\ Joscif Raigne', Naveen A. Thaiparambil', Noureddine El Haddad ${ }^{5,6}$, Bharath Raja ${ }^{4}$, \\ Wanyan Wang ${ }^{7}$, Antonella Ferela ${ }^{1}$, Kevin O. Chiteri ${ }^{1}$, Mahendar Thudi ${ }^{8,9}$, \\ Rajeev K. Varshney ${ }^{10,11}$, Surinder Chopra ${ }^{12}$, Arti Singh ${ }^{1}$ and Asheesh K. Singh ${ }^{1}$ \\ ${ }^{1}$ Department of Agronomy, lowa State University, Ames, IA, United States, ${ }^{2}$ VIT School of Agricultural Innovations \\ and Advanced Learning, Vellore Institute of Technology, Vellore, India, ${ }^{3}$ Division of Crop Improvement, ICAR-Sugarcane \\ Breeding Institute, Coimbatore, India, ${ }^{4}$ School of Biosciences and Technology, Vellore Institute of Technology, Vellore, India, \\ ${ }^{5}$ International Center for Agricultural Research in the Dry Areas, Rabat, Morocco, ${ }^{6}$ Faculty of Sciences, Mohammed V \\ University of Rabat, Rabat, Morocco, ${ }^{7}$ Ecosystem Science and Management, Penn State University, University Park, PA, \\ United States, ${ }^{8}$ Department of Agricultural Biotechnology and Molecular Biology, Dr. Rajendra Prasad Central Agricultural \\ University, Pusa, India, ${ }^{9}$ Centre for Crop Health, University of Southern Queensland, Toowoomba, QLD, Australia, \\ ${ }^{10}$ International Crops Research Institute for the Semi-Arid Tropics, Patancheru, India, ${ }^{11}$ State Agricultural Biotechnology \\ Centre, Crop Research Innovation Centre, Food Futures Institute, Murdoch University, Murdoch, WA, Australia, \\ ${ }^{12}$ Department of Plant Science, Penn State University, University Park, PA, United States
}

Sangeeta Dhaubhadel, London Research and Development Centre, Agriculture and Agri-Food

Canada, Canada

Reviewed by:

Enrico Doria,

University of Pavia, Italy

Sudhir P. Singh,

Center of Innovative and Applied

Bioprocessing (CIAB), India

*Correspondence:

Dinakaran Elango

delango@iastate.edu

orcid.org/0000-0003-2226-486X

Specialty section:

This article was submitted to

Plant Metabolism

and Chemodiversity,

a section of the journal

Frontiers in Plant Science

Received: 04 December 2021

Accepted: 26 January 2022

Published: 17 February 2022

Citation:

Elango D, Rajendran K, Van der Laan L, Sebastiar S Raigne J, Thaiparambil NA, El Haddad N, Raja B, Wang W,

Ferela A, Chiteri KO, Thudi M, Varshney RK, Chopra S, Singh A and Singh AK (2022) Raffinose Family Oligosaccharides: Friend or Foe for Human and Plant Health?

Front. Plant Sci. 13:829118. doi: 10.3389/fp/s.2022.829118
Raffinose family oligosaccharides (RFOs) are widespread across the plant kingdom, and their concentrations are related to the environment, genotype, and harvest time. RFOs are known to carry out many functions in plants and humans. In this paper, we provide a comprehensive review of RFOs, including their beneficial and anti-nutritional properties. RFOs are considered anti-nutritional factors since they cause flatulence in humans and animals. Flatulence is the single most important factor that deters consumption and utilization of legumes in human and animal diets. In plants, RFOs have been reported to impart tolerance to heat, drought, cold, salinity, and disease resistance besides regulating seed germination, vigor, and longevity. In humans, RFOs have beneficial effects in the large intestine and have shown prebiotic potential by promoting the growth of beneficial bacteria reducing pathogens and putrefactive bacteria present in the colon. In addition to their prebiotic potential, RFOs have many other biological functions in humans and animals, such as anti-allergic, anti-obesity, anti-diabetic, prevention of nonalcoholic fatty liver disease, and cryoprotection. The wide-ranging applications of RFOs make them useful in food, feed, cosmetics, health, pharmaceuticals, and plant stress tolerance; therefore, we review the composition and diversity of RFOs, describe the metabolism and genetics of RFOs, evaluate their role in plant and human health, with a primary focus in grain legumes.

Keywords: $\alpha$-galactosides, flatulence, galactinol synthase, prebiotic carbohydrates, grain legume crops

\section{WHAT ARE RAFFINOSE FAMILY OLIGOSACCHARIDES?}

Raffinose family oligosaccharides (RFOs) are soluble carbohydrates ranked next to sucrose in their distribution in higher plants (French, 1954; Keller and Pharr, 1996). They are abundant in the seed of many crops, particularly in the legume family, e.g., soybean (Glycine max), lentil (Lens culinaris), and chickpea (Cicer arietinum). They are also present in roots and specialized storage organs such 
as tubers and leaves. For example, the RFOs concentration is up to $25-80 \%$ of their dry weight in tubers of Chinese artichoke (Stachys sieboldii) and photosynthesizing leaves of a common bugle (Ajuga reptans) (Bachmann and Keller, 1995; Tahir et al., 2011). However, due to the lack of $\alpha$-galactosidase to degrade RFOs (Calloway and Murphy, 1968; Han and Baik, 2006), they are neither absorbed nor hydrolyzed in the upper gastrointestinal tract of humans and get accumulated in the large intestine of the human digestive system. Eventually, the $\alpha$-galactosides undergo microbial fermentation by colonic bacteria resulting in hydrogen, methane, and $\mathrm{CO}_{2}$ production - major components of flatulent gases (Singh, 1985). RFOs are indigestible and cause flatulence in humans (Gupta, 1987; Van den Ende, 2013; Sengupta et al., 2015; Gangl and Tenhaken, 2016). Expulsion of these gases causes severe abdominal discomfort such as abdominal rumblings, cramps, diarrhea, and nausea (Sosulski et al., 1982; Kennedy et al., 1985; Lee et al., 2007).

The production of galactinol initiates the biosynthesis of RFOs by galactinol synthase, which catalyzes the galactosyl residue from UDP-D-galactose to myoinositol (Peterbauer and Richter, 2001; Panikulangara et al., 2004). Two pathways have been identified as RFO biosynthetic pathways (Figure 1). The first pathway, and the more common of the two, is galactinol dependent. This pathway starts with UDP-galactose and myoinositol as precursors. Galactinol synthase catalyzes the transfer of a galactosyl moiety from UDP-galactose to myoinositol, forming galactinol (Peterbauer and Richter, 2001). The next step in the pathway is catalyzed by the raffinose synthase, which transfers a galactosyl moiety from the previously formed galactinol to sucrose, forming raffinose, the first RFO in the biosynthetic pathway (Peterbauer et al., 2002a). Following the formation of raffinose, the larger RFOs stachyose and verbascose can be formed. The formation of stachyose is catalyzed by stachyose synthase, similar to the formation of raffinose; a galactosyl moiety is transferred from galactinol. During this reaction, raffinose is the acceptor instead of sucrose. The verbascose formation is also similar, except stachyose is now the galactosyl acceptor. The enzyme responsible for catalyzing this reaction has yet to be recognized (Lahuta et al., 2010); however, in peas (Pisum sativum), stachyose synthase is used as a multifunctional enzyme in synthesizing both stachyose and verbascose (Peterbauer et al., 2003).

The second RFO biosynthetic pathway is galactinol independent (Figure 1). This pathway is less common than the first and has only been reported in two species of the Lamiaceae family: Ajuga reptans and Coleus blumei (Bachmann and Keller, 1995; Gilbert et al., 1997). This pathway can only produce the larger RFOs of stachyose and verbascose. To form these RFOs, the enzyme galactan-galactan galactosyl transferase (GGT) catalyzes the transfer of a galactosyl moiety from one RFO, such as raffinose, to another RFO. In the formation of stachyose, two raffinose molecules act as donors and acceptors to form a single stachyose. Verbascose is formed by GGT catalyzing the transfer of galactosyl from raffinose to stachyose. The GGT enzyme has only been found in the vacuoles of leaves (Bachmann and Keller, 1995; Peterbauer et al., 2002b).
Raffinose family oligosaccharides can be reduced at varying degrees based on the food preparation involved. Food processing techniques including soaking, germination, decortications, fermentation, cooking, and use of enzymes such as $\alpha$ galactosidase (which can catalyze the hydrolysis of RFO) can significantly increase the level of soluble dietary fiber fraction, reduce the levels of $\alpha$-galactosides and hence enhance the digestibility of the food (Jood et al., 1985; Egbe and Akinyele, 1990; Aguilera et al., 2009). However, these food processing methods are time-consuming and lead to loss of nutrients and sometimes have consumer acceptability issues. Therefore, alternative approaches from a breeding perspective have been used to select cultivars with a low level of raffinose and stachyose (Obendorf and Górecki, 2012; Redekar et al., 2020) or inhibiting galactinol synthase activity (Bock et al., 2009) and over-expression of $\alpha$-galactosidase in seeds by genetic manipulation (Polowick et al., 2009). Screening legumes for low RFOs contents has been carried out in many species such as chickpea (Raja et al., 2015; Gangola et al., 2016), lentil (Tahir et al., 2011, 2012), pea (Peterbauer et al., 2003), and soybean (Blackman et al., 1992; Dierking and Bilyeu, 2008; Obendorf and Górecki, 2012). Many breeding programs of grain legumes aim to decrease the content of antinutritional factors via genetic means to a safe extent to increase the level of grain legumes in human and animal diets.

Moreover, RFOs have recently been reported to have a beneficial effect on the gut microflora. Therefore, they are recommended in human diets to prevent cancer in the digestive tract (Van den Ende, 2013). The oligosaccharide family of raffinose has a wide range of predicted functions. In addition, being a form of carbohydrate storage and transport, the raffinose members play an important role in abiotic stresses, such as high salinity and drought (Taji et al., 2002; Nishizawa-Yokoi et al., 2008; Dobrenel et al., 2013; Van den Ende, 2013). Due to their membrane-stabilizing, antioxidant properties, and perhaps expected signaling roles, RFOs are emerging as crucial molecules during stress responses in plants (Van den Ende, 2013). We aim to comprehensively review the literature about RFOs and their role in human and plant health with this background.

\section{RAFFINOSE FAMILY OLIGOSACCHARIDES DIVERSITY IN CROPS}

Raffinose family oligosaccharides are well documented in many cereals, pulses, fruits, and vegetables (Vidal-Valverde et al., 1993; Frias et al., 1994; Andersen et al., 2005; Wang and Daun, 2006; Huynh et al., 2008). The below table summarizes the genetic variability of different oligosaccharide components present in the grain legumes (Table 1). Range and mean values of each RFO component were presented, wherein some authors reported as range and others reported as mean.

\section{Peas}

Considerable variation in the total $\alpha$-galactoside concentration and composition exists in pea cultivars (Sosulski et al., 1982; Jones et al., 1999; Vidal-Valverde et al., 2003; Asif et al., 2013). In a study 


\section{Galactinol Dependent}

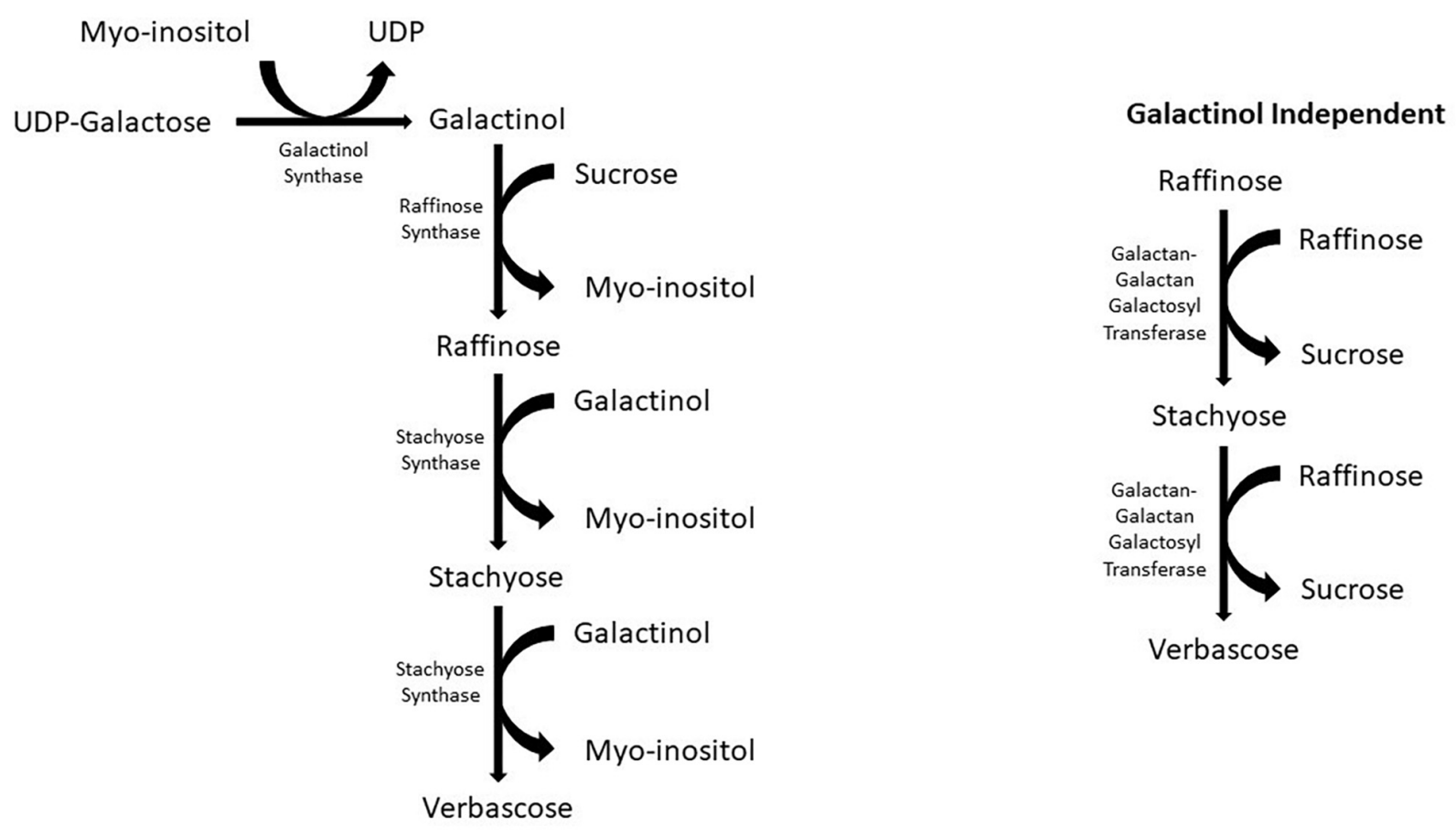

FIGURE 1 | Galactinol dependent and independent biosynthetic pathways for RFO biosynthesis in crop plants.

of 18 pea cultivars, total $\alpha$-galactosides concentration ranged from 22.6 to $63.4 \mathrm{~g} \mathrm{~kg}^{-1}$ of dry matter (Vidal-Valverde et al., 2003). Stachyose and verbascose contents were higher compared to raffinose content (Jones et al., 1999; Vidal-Valverde et al., 2003; Asif et al., 2013).

\section{Soybean}

Sucrose was the major sugar found in the 241 soybean plant introductions (PIs), ranging from 1.6 to $95.4 \mathrm{mg} \mathrm{g}^{-1}$, with most of the germplasm containing 30 to $70 \mathrm{mg} \mathrm{g}^{-1}$ sucrose (Hou et al., 2009a). The raffinose content in 241 PIs ranged from 0.1 to $19.9 \mathrm{mg} \mathrm{g}^{-1}$ with a mean of $8.3 \mathrm{mg} \mathrm{g}^{-1}$, with most of the germplasm containing 5 to $10 \mathrm{mg} \mathrm{g}^{-1}$. The total sugar content in 241 PIs followed a normal distribution ranging from 16.4 to $190.1 \mathrm{mg} \mathrm{g}^{-1}$, with a mean of $96.4 \mathrm{mg} \mathrm{g}^{-1}$. In another study, Hymowitz and Collins (1974) and Hartwig et al. (1997) found that raffinose was a minor sugar, whereas stachyose was the second major sugar after sucrose. The stachyose content ranged from 0.2 to $69.6 \mathrm{mg}^{-1}$ with a mean of $31.7 \mathrm{mg}^{-1}$ and the majority having 30 to $40 \mathrm{mg}^{-1}$ (Hymowitz and Collins, 1974; Hartwig et al., 1997). The total sugar concentration is in the range of 70 to $120 \mathrm{mg} \mathrm{g}^{-1}$ (Hymowitz and Collins, 1974; Hartwig et al., 1997).

The RFOs found in most soybean cultivars were stachyose and raffinose. They made up to approximately $4-6 \%$ of soybean flour on a dry weight basis (Grieshop et al., 2003). Kennedy et al. (1985) reported that the coefficient of variation for the soybean samples were $3.5 \%, 5.3 \%$, and $10.5 \%$, respectively, for sucrose, stachyose, and raffinose. The average raffinose and stachyose content in the defatted soy flour was $1.15 \%$ and $3.23 \%$, respectively. In soybean, the reduction in raffinose synthase enzyme activity was reported in the developing seeds, which means the developing seeds accumulate more sucrose than RFOs (Hitz et al., 2002).

The total $\alpha$-galactosides concentration in soybean was 6.0 to

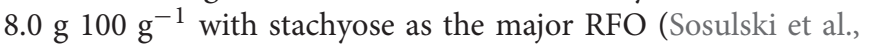
1982). RFO accounted for more than $50 \%$ of total soluble sugars in cowpea and soybean. Giannoccaro et al. (2008) quantified the major sugars, including glucose, fructose, sucrose, raffinose, and stachyose in five soybean lines. The amount of each sugar five soybean lines ranged $0.07-0.15 \%$ for glucose, $0.08-0.19 \%$ for fructose, $5.64-9.39 \%$ for sucrose, $0.25-1.35 \%$ for raffinose, and 0.29-6.33\% for stachyose.

Kumar et al. (2010) examined the ranges of sucrose and total RFO content in 48 soybean genotypes using the enzymatic rapid assay method. Sucrose content ranged from 3.45 to $16.55 \mathrm{mmol}$ $100 \mathrm{~g}^{-1}$ with a mean value of $8.90 \mathrm{mmol} 100 \mathrm{~g}^{-1}$. Total RFO content varied from 3.5 to $9.22 \mathrm{mmol} 100 \mathrm{~g}^{-1}$ with a mean

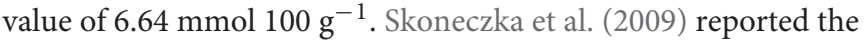
stachyose content in wild-type and mutant types. The stachyose content for the wild type and mutant line ranged from 0.56 to $0.89 \%$ and 0.69 to $1.47 \%$, respectively. Trugo et al. (1995) reported a range of 0.4 to 1.4 and 4.8 to $6.9 \mathrm{mmol} 100 \mathrm{~g}^{-1}$ for raffinose and stachyose, respectively, in the 20 Brazilian soybean genotypes.

\section{Chickpea}

Raffinose family oligosaccharides and sucrose are the major soluble carbohydrates found in chickpeas. The RFOs includes 
raffinose, stachyose, verbascose, and ciceritol. It was found that stachyose and raffinose accounted for $27.3 \%$ and $7.7 \%$ of total soluble sugars in chickpea (Lineback and Ke, 1975). Singh et al. (1982) recorded the concentrations of total soluble sugars and oligosaccharides in eight Desi and seven Kabuli type chickpea cultivars grown in Hissar, India. They found stachyose and raffinose accounted for $26.7 \%$ and $10.2 \%$ of the total soluble sugars in those varieties. Similarly, Saini and Knights (1984) studied the variation for total oligosaccharides in seven desi and Kabuli chickpea varieties. They revealed that Kabuli chickpeas had 3.2\% higher total oligosaccharide levels than desi varieties. Kabuli chickpeas had 1.47, 5.30, and $0.12 \mathrm{~g}$ $100 \mathrm{~g}^{-1}$ of raffinose, stachyose, and verbascose, respectively:

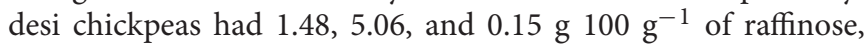
stachyose, and verbascose, respectively (not presented in the table). A study by Mulimani and Ramalingam (1997) reported

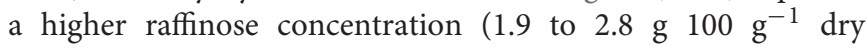
matter) than the total amount of stachyose and verbascose

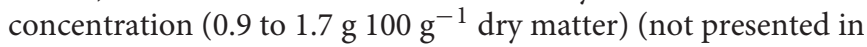
the table).

The chromatographic profile of three raw Spanish chickpea cultivars was observed and the soluble sugar content was quantified by Sánchez-Mata et al. (1998). Among disaccharides, sucrose was the leading one, accounting for $28 \%$ of the total sugar content. The $\alpha$-galactoside group was around $60 \%$ of the total sugar content in raw samples. Ciceritol comprised about $40 \%$ of total sugars in chickpea samples analyzed. Other $\alpha$ galactosides in total, when analyzed in raw chickpea, ranged from $1.31 \mathrm{mg} 100 \mathrm{~g}^{-1}$ to $1.95 \mathrm{mg} 100 \mathrm{~g}^{-1}$ and represented $19.4 \%$ to $22.3 \%$ of the total amount of sugars. Figure 2 captures the oligosaccharide variation present in the International Crops Research Institute for the Semi-Arid Tropics (ICRISAT) minicore collection of chickpeas (Ramadoss et al., 2015). Kabuli chickpeas had higher total sugars and sucrose levels, whereas desi had higher levels of RFOs, including raffinose, stachyose, and ciceritol (Figure 2). Germination considerably reduced the accumulation of RFOs in chickpea seeds (Åman, 1979), and according to Xiaoli et al. (2008), chickpea sample 171 has the desirable sugar profile and could be used in breeding programs to develop ideal sugar types.

\section{Lentil}

Significant variations were observed for $\alpha$-galactosides in lentil seeds ranging from 1.8 to $7.5 \%$ (Wang and Daun, 2006; Martínez-Villaluenga et al., 2008). Sucrose concentration of

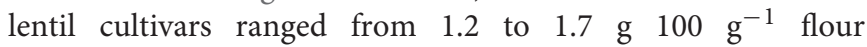
with a mean concentration of $1.4100 \mathrm{~g}^{-1}$ flour. Total RFO concentration of lentil cultivars varied from 4.5 to 5.5 moles $100 \mathrm{~g}^{-1}$ flour. Johnson et al. (2021) found 7 to $31 \%$ variation for RFOs in lentil seeds from 143 accessions. Significant differences were observed between different years of lentil harvest. The year 1995 harvest exhibited higher total $\alpha$ galactosides compared to the year 1994 harvest (Sánchez-Mata et al., 1998), which explains the accumulation of soluble sugars is highly dependent on the environment and tissue and is genotype-specific (Sánchez-Mata et al., 1998; Han and Baik, 2006; Martínez-Villaluenga et al., 2008).

\section{Faba Bean}

Sosulski et al. (1982) studied variation in the concentration of $\alpha$-galactoside in 11 legumes and reported verbascose is the predominant $\alpha$-galactoside in faba bean. Vidal-Valverde et al. (1998) observed high levels of verbascose (2.29\% of dry weight), followed by stachyose ( $1.10 \%$ of dry weight) and raffinose $(0.28 \%$ of dry weight) in faba bean. Lattanzio et al. (1986) reported the oligosaccharides content in fresh and dry mature seeds of fifteen cultivars of faba bean lines. The raffinose content of the whole dry seeds ranged from 0.12 to $0.29 \%$; stachyose content between 0.46 and $1.02 \%$; and verbascose content between 0.82 and $1.61 \%$ on a dry matter basis.

\section{Lupins}

A wide variation for RFO concentration and its composition was reported among the lupin species: it had 0.30-1.90, 2.30-8.60, and ND (non-detectable)-3.50 percent of raffinose, stachyose, and verbascose, respectively (Martínez-Villaluenga et al., 2008). Ajugose had an exclusive presence in lupin seeds: L. albus, L. mutabilis had the lowest level of ajugose $(0.2-0.5 \%$ and $0.2 \%$, respectively), followed by L. angustifolius (1.7-2.6\%) and L. luteus (0.6-4.6\%) (Trugo et al., 1988). Trugo et al. (1988) studied the RFO content and sucrose in various lupin species. They found significant variations in the levels of individual RFO among lupin species. L. albus seeds had the verbascose (0.4\%); L. luteus had stachyose $(7.4 \%)$, verbascose $(3.1 \%)$, sucrose $(1.2 \%)$, and L. angustifolius had sucrose (3.4\%) and stachyose (4.6\%). There was a wide variation in total $\alpha$-galactosides between species, with a remarkably high content found in L. luteus (9.5-12.3\%).

\section{Lima Beans}

The effect of oligosaccharides on germination was investigated in lima beans (Dibofori et al., 1994). The sucrose content increased

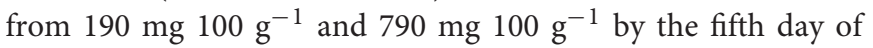
germination. On the other hand, raffinose decreased from $620 \mathrm{mg}$

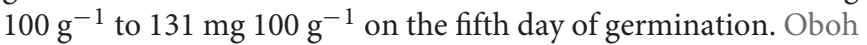
et al. (2000) reported the total $\alpha$-galactoside contents of the seeds in the mature seeds in white lima beans $\left(3.62 \mathrm{mg} 100 \mathrm{mg}^{-1}\right)$ and red lima beans ( $3.37 \mathrm{mg} 100 \mathrm{mg}^{-1}$ ). They found stachyose was the predominant sugar in lima beans.

\section{Black Gram (Urd Bean)}

Reddy and Salunkhe (1980) reported RFO concentration in long-grain polished rice and black gram. They did not find RFO in rice but higher verbascose concentration (3.44\%), followed by stachyose $(0.89 \%)$ and raffinose (trace) in black gram. Souframanien et al. (2014) also reported higher verbascose concentration (14 to $31 \mathrm{mg} \mathrm{g}^{-1}$ ), followed by stachyose ( 8.9 to $\left.37.3 \mathrm{mg} \mathrm{g}^{-1}\right)$ and raffinose $\left(0.2\right.$ to $\left.8.1 \mathrm{mg} \mathrm{g}^{-1}\right)$ in black gram.

\section{Green Gram (Mung Bean)}

Verbascose was the prominent RFO sugar in green gram (Åman, 1979; Sosulski et al., 1982; Asif et al., 2013). Germination completed nullified the presence of RFOs in green gram compared to the raw seeds (Åman, 1979; Mubarak, 2005). Hence, 
TABLE 1 | Variability of oligosaccharides present in the various grain legumes.

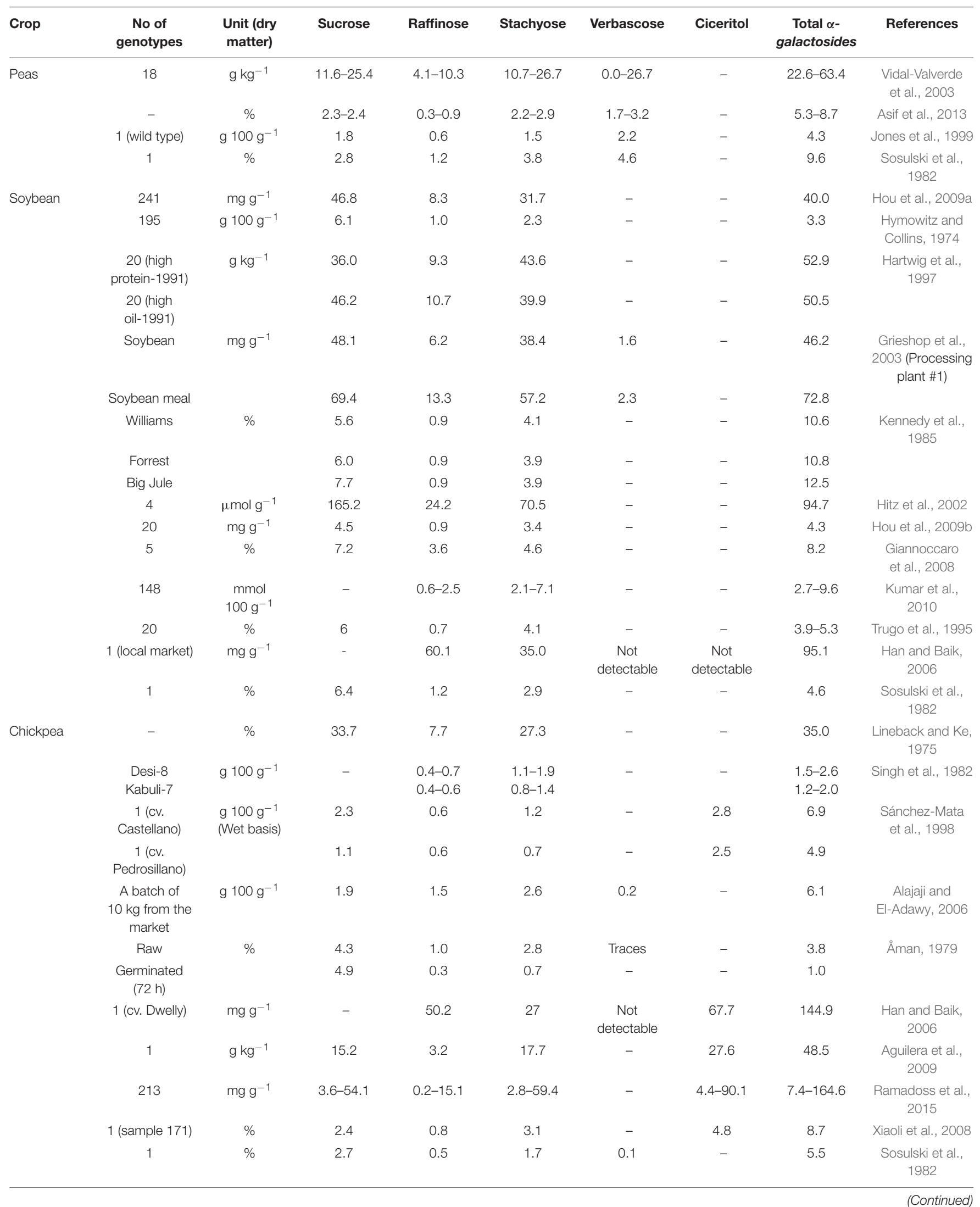


TABLE 1 | (Continued)

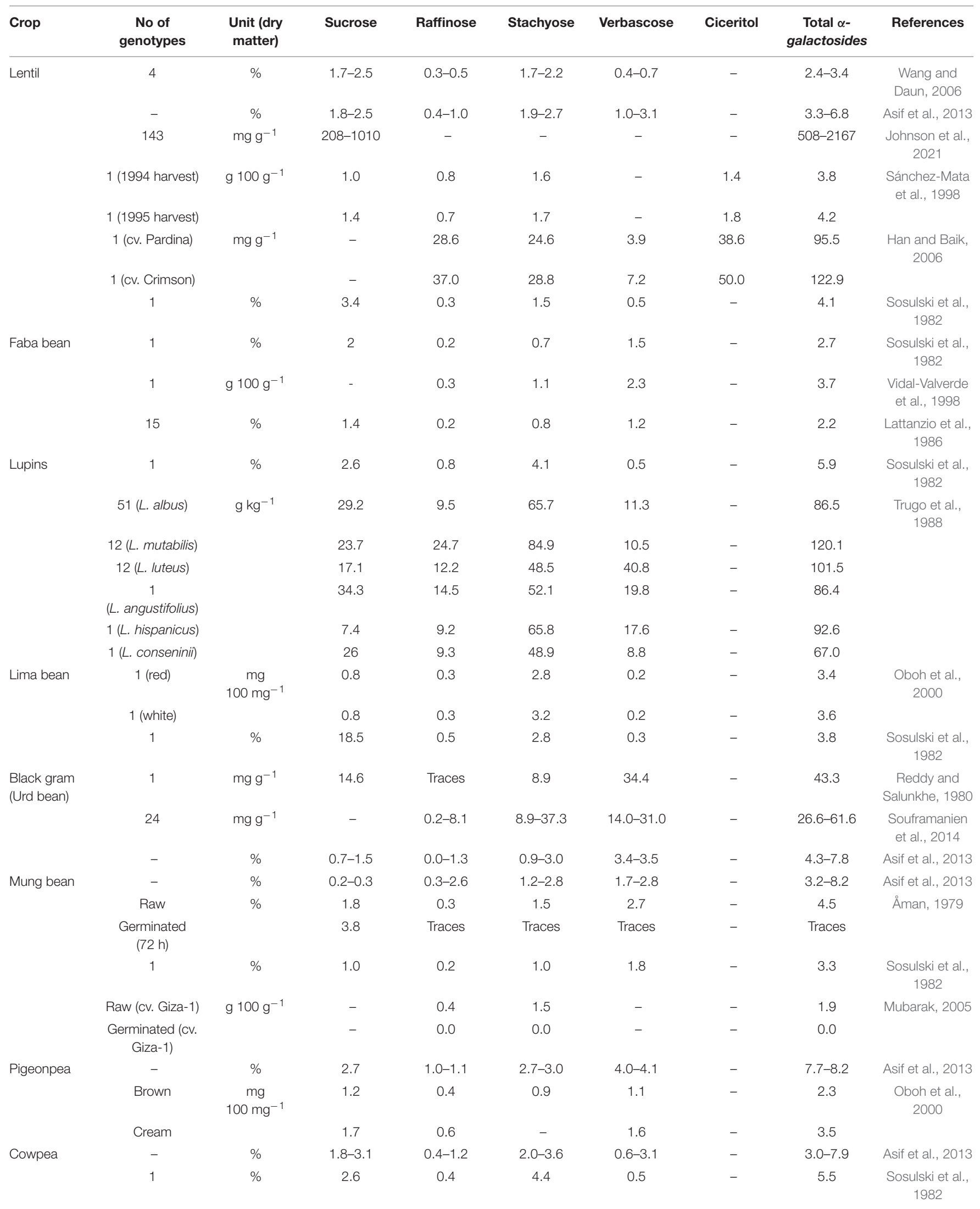




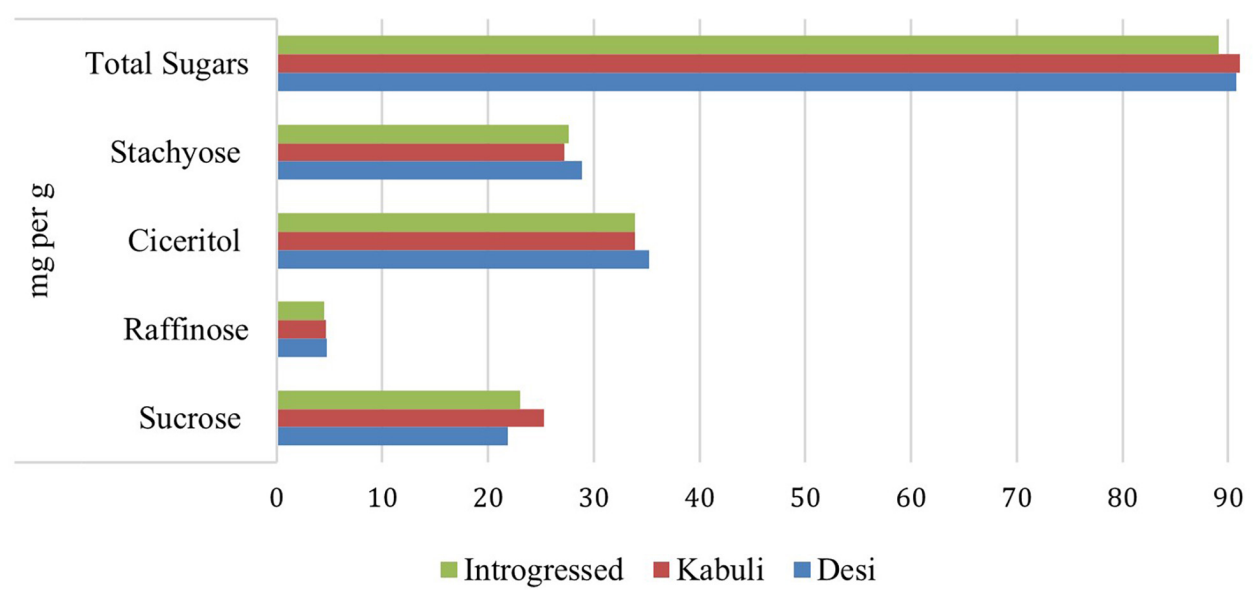

FIGURE 2 | Oligosaccharide variations in the ICRISAT chickpea mini-core collection.

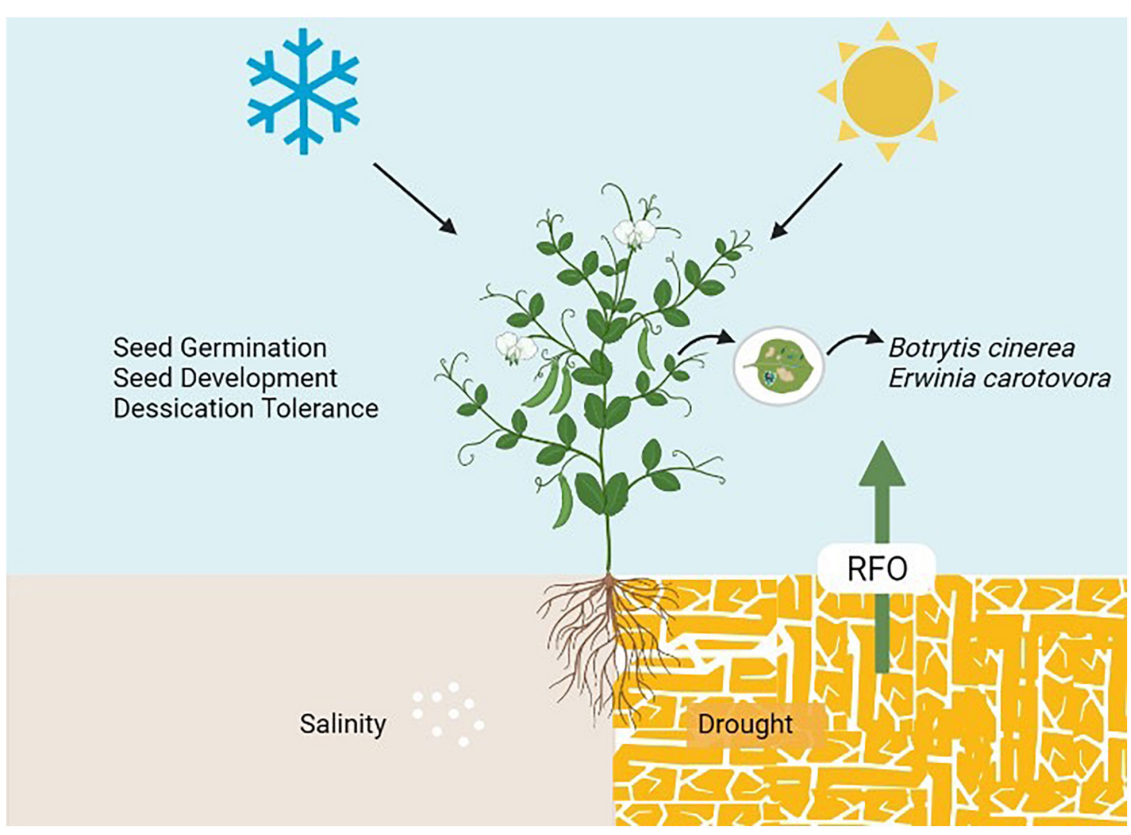

FIGURE 3 | Multi-functional role of RFOs in plant health.

consuming sprouted seeds of mung bean is the effective alternate strategy to avoid flatulence problems in human beings.

\section{Other Grain Legumes}

The raffinose $\left(3.7 \mathrm{mg} \mathrm{g}^{-1}\right)$ and stachyose $\left(23.6 \mathrm{mg} \mathrm{g}^{-1}\right)$ contents were reported in dry bean varieties (Sosulski et al., 1982). Dry bean varieties grown in the United States have about 2$10 \mathrm{mg} \mathrm{g}^{-1}$ of raffinose and 2-56.2 $\mathrm{mg} \mathrm{g}^{-1}$ of stachyose (Salunkhe and Kadam, 1989). Oboh et al. (2000) quantified the total $\alpha$ galactoside contents in the mature seeds of pigeon peas, African yam beans, and jack beans. The total $\alpha$-galactoside contents of the seeds in decreasing order were African yam beans $(3.84 \mathrm{mg}$ $100 \mathrm{mg}^{-1}$ ); cream pigeon peas (3.52 mg $100 \mathrm{mg}^{-1}$ ); jack beans (2.83 mg $100 \mathrm{mg}^{-1}$ ), and brown pigeon peas $(2.34 \mathrm{mg}$ $\left.100 \mathrm{mg}^{-1}\right)$. Stachyose was the predominant sugar in jack beans and African yam beans, while verbascose was the predominant oligosaccharides in pigeon pea. Stachyose was the prominent sugar in cowpea (Sosulski et al., 1982; Asif et al., 2013).

\section{METABOLISM AND GENETICS OF RAFFINOSE FAMILY OLIGOSACCHARIDES}

Raffinose family oligosaccharides are $\alpha$-D-galactosides of sucrose, a di-saccharide. They also occur in forms such as raffinose, 
stachyose, verbascose, and ajugose, belonging to trisaccharide, tetrasaccharide, pentasaccharide, and hexasaccharide groups, respectively (Bachmann and Keller, 1995; Vanhaecke et al., 2006, 2008, 2010). From the structural perspective, they are considered $\alpha$-galactosyl derivatives of sucrose. Raffinose contains galactose, glucose, and fructose. Stachyose holds two $\alpha$-Dgalactose units, one $\alpha$-D-glucose unit, and one $\beta$-D-fructose unit. Besides galactinol synthase, raffinose synthase and stachyose synthase are the other two major enzymes involved in the RFO biosynthesis pathway. Raffinose synthase transfers a galactinol moiety from galactinol to sucrose and produces raffinose, while the stachyose synthase utilizes galactinol to synthesize tetrasaccharide stachyose. Both reactions are reversible (Sengupta et al., 2015). However, the enzyme responsible for the biosynthesis of verbascose has not been recognized yet (Lahuta et al., 2010). Peterbauer et al. (2003) reported that stachyose synthase is the most probably responsible enzyme due to its multifunctional character. Recently, Kannan et al. (2018) have noted that the verbascose synthase is the chief enzyme that catalyzes the synthesis of verbascose by adding a galactosyl residue from galactinol to stachyose. Nevertheless, the synthesis of the pentasaccharide verbascose and higher homologs is galactinol-dependent. They may include $\alpha$-galactosyl derivatives of the cyclitols myo-inositol, D-pinitol, D-chiro-inositol, and Dononitol but with small amounts (Obendorf and Górecki, 2012).

Raffinose family oligosaccharides are ubiquitous and can be directly extracted from the plant materials using water or aqueous ethanol, or methanol solutions. Raffinose is mainly extracted from sugar beets during sugar processing in Japan (Dinoto et al., 2006). But traditional methods of extraction processes often yield low and fetch high production costs (Han et al., 2019). Therefore, high throughput, a cost-effective, environmentfriendly method is imperative. Several researchers have focused on the production of $\alpha$-galactosidase using microorganisms, which offer great potential for enzyme production due to high expression levels and extracellular secretion into the medium, promoting easier downstream processing. Filamentous fungi were the most sought microbial source exploited extensively for the synthesis of $\alpha$-galactosidase and have been used in multiple biotechnological and medical applications (Katrolia et al., 2014). Numerous investigations have been reported the production of $\alpha$-galactosidase originated from several fungi such as Aspergillus niger, Aspergillus parasiticus, Cladosporium cladosporides, and Aspergillus niger (Mansour and Khalil, 1998), and Pestalotiopsis microspora (Yang et al., 2015). Likewise, the $\alpha$-galactosidase gene has been characterized from many bacterial sources such as Bacillus stearothermophilus (Gote et al., 2004, 2006) and Thermotoga maritima (Comfort et al., 2007). Fridjonsson et al. (1999) isolated the enzyme designated $\operatorname{AgaN}$, a similar gene to $\alpha$-galactosidase from Bacillus stearothermophilus. The enzyme showed high thermostability and displays a high affinity for oligomeric substrates, including the raffinose, and can hydrolyze raffinose in the presence of $60 \%$ sucrose with high efficiency.

Recently, Huang et al. (2018) characterized a novel $\alpha$ galactosidase $(\mathrm{AgaB})$ from Bacillus megaterium and exhibited high activity in the intestine. The $A g a B$ gene completely hydrolyzed raffinose and stachyose and rapid hydrolysis of RFO in soybean milk at $37^{\circ} \mathrm{C}$ within $4 \mathrm{~h}$ when combined with trypsin. Likewise, Aga-BC7050 is a novel $\alpha$-galactosidase of glycoside hydrolase family cloned from Bacillus coagulans and was highly active toward raffinose and stachyose (Zhao et al., 2018). Aga$B C 7050$ showed great resistance to proteinase and trypsin, not inhibited by monosaccharides, and completely hydrolyzed raffinose and stachyose in less than $30 \mathrm{~min}$. Furthermore, two genes (agal1 and agal2) encoding a-galactosidase were identified by sequence-based screening approaches from two thermophilic bacteria (Schröder et al., 2017). Qiu et al. (2015) identified and characterized a mutant gene of soybean stachyose (STS) gene controlling the reduction of stachyose and raffinose content up $90 \%$ in soybean seeds also confirmed the function of STS gene in converting raffinose into stachyose as part of raffinose metabolism.

Utilization of altered raffinose synthase 2 (RS2) alleles is the straightforward genetic approach to high sucrose and low RFOs trait. The enzyme RS2 is galactinol-sucrose galactosyltransferase and is considered the committed step in the biosynthesis of raffinose and the free cyclitol myo-inositol. In soybean, variant alleles of the RS2 gene have been identified and showed a high capacity in decreasing RFOs and increasing sucrose content, which may improve metabolizable energy in soybean meal (Dierking and Bilyeu, 2008, 2009; Skoneczka et al., 2009). Bilyeu and Wiebold (2016) demonstrated that altered carbohydrate soybeans produce high sucrose $(>8 \%$ dry) and low RFOs (1\% total raffinose and stachyose) phenotype across different environments with contrasting alleles of the RS2 gene. Similarly, Valentine et al. (2017) used RNA-mediated gene silencing to down-regulate the soybean gene RS2. They identified increased true metabolizable energy (from 2.41 to $2.70 \mathrm{kcal} \mathrm{kg}^{-1}$ ) in poultry feed using transgenic soybean lines, which exhibited intensely reduced raffinose levels in mature seed. RS3 and RS4 genes with polymorphisms that contributed to the ultra-low raffinose and stachyose content and identified a novel mutant allele designated SG-ULRFO derived from soybean, which resulted in an ultra-low raffinose and stachyose phenotype (Schillinger et al., 2013). Hagely et al. (2020) suggested that the combination of $R S 2$ and RS3 alleles produce ultra-low phenotypes in soybean. On the other hand, a strong relationship between RFOs and abscisic acid (ABA) in mature seeds of alfalfa, where the amount of galactinol, raffinose, and stachyose accumulated was much higher ( $>$ threefold) at the highest ABA concentration (Blöchl et al., 2005). This accumulation was attended by a threefold increase in galactinol synthase activity, while the levels of raffinose synthase and stachyose synthase activities persisted almost constant. In addition, high ABA applications declined the content of monosaccharides (glucose and fructose).

On the other hand, $\alpha$-galactosidases are classified into several glycoside hydrolases (GH) families, such as GH4, GH27, GH36, and GH57. However, most characterized $\alpha$-galactosidases are assigned into the evolutionary related GH27 and GH36, which together with GH31 represent clan $\mathrm{GH}-\mathrm{D}$ comprising a common fold and handling double displacement mechanism (Comfort et al., 2007). Most GH36 $\alpha$-galactosidases were characterized as tetramers, often larger enzymes of about $85 \mathrm{kDa}$ (Garro et al., 1993; Nakai et al., 2010). A new gene encoding a 
putative $\alpha$-galactosidase (CbAga36) from C. bescii was cloned and sequenced (Lee et al., 2017). The size exclusion chromatography indicated that its native form was a tetramer. CbAga36 was grouped as members of the clan GH-D, exhibiting high similarity to the family of glycoside 36 . Besides, the purified recombinant of CbAga36 demonstrated preferential activity toward the hydrolysis of RFO, and the enzyme activities were stable at hightemperature levels ranging from 60 to $75^{\circ} \mathrm{C}$. The inheritance pattern of total $\alpha$-galactoside and individual RFO compounds and ciceritol were determined using embryos and the seed coat from single seeds of the reciprocal crosses (Frias et al., 1999). Within $\alpha$-galactosides, raffinose was usually present in embryos in the lowest amount, not varying between the parental, $\mathrm{F}_{1}$, and $\mathrm{F}_{2}$ generations. However, a wider variation was found between the ten $\mathrm{F}_{3}$ families, ranging from 0.3 to $0.6 \%$. Stachyose formed a significant proportion of the total $\alpha$-galactosides found in all embryos. The mean values for the parental lines were similar to each other (2.3\% and $2.5 \%$, respectively) and the level found in reciprocal. The widest variation between the parental lines was found for verbascose content, ranging from 0.6 to $1.0 \%$.

\section{ROLE OF RAFFINOSE FAMILY OLIGOSACCHARIDES IN PLANT HEALTH}

The importance of RFOs in plant health is still an area of interest for researchers; and has many gaps to fill even after years of study. Till now, it is known that they have a crucial role in plant physiology and cellular functions as signal transduction (Stevenson et al., 2000; Xue et al., 2007), membrane trafficking, mRNA export and transport, carbon storage (Thole and Nielsen, 2008; Okada and Ye, 2009), desiccation tolerance (MartínezVillaluenga et al., 2008), seed storability (Horbowicz and Obendorf, 1994), biotic and abiotic stress tolerance (Nishizawa et al., 2008; Nishizawa-Yokoi et al., 2008), photoassimilate translocation (Dinant and Lemoine, 2010), and seed germination (Blöchl et al., 2007). The role of RFOs in plant health is further discussed below.

\section{Carbon Storage and Translocation}

Plants store and translocate fixed carbon anticipating the worst fluctuation in the environmental conditions, which may eventually reduce carbon supply. Most of the time, they store carbon in the form of starch while translocating them in sucrose. However, certain plant species can store and translocate alternate carbohydrates like RFOs (Kandler and Hopf, 1982). For example, the plant family members; Cucurbitaceae, Lamiaceae, Oleaceae, and Scrophulariaceae transports RFOs through phloem by forming a symplasm with mesophyll and sieve elements (Beebe and Turgeon, 1992; van Bel, 1993; Turgeon, 1996).

\section{Abiotic and Biotic Stress Tolerance}

Even though RFOs are derived from an extended metabolic pathway of inositol, they don't directly involve in plants' stress amelioration under natural conditions, unlike other products derived from the same pathway (Loewus and Murthy, 2000; Sengupta et al., 2012). A subsequent increase of RFOs (especially raffinose) has been observed in several cases of abiotic stresses such as heat, cold, salinity, or drought (Santarius and Milde, 1977; Bachmann et al., 1994; Taji et al., 2002; Pennycooke et al., 2003; Panikulangara et al., 2004; NishizawaYokoi et al., 2008; Peters and Keller, 2009; Peters et al., 2010). However, there is not much information explaining the specific functional roles of RFOs in abiotic stress tolerance. Several other molecules (e.g., sucrose and proline) with characterized roles in abiotic stress amelioration also tend to accumulate under such conditions. Reports have also suggested that genetic elimination of biosynthetic enzymes associated with RFOs does not affect plants drastically (Panikulangara et al., 2004), adding further evidence to the above fact. On the contrary, certain studies claim that RFOs do have beneficial properties of a compatible solute. For example, research by Hincha et al. (2003) suggests that RFOs stabilize the cell membrane during dehydration stress by inserting themselves within the lipid head groups of the membrane bilayer. Farrant (2007) added further proof to this fact by correlating the phenomenon of increase in RFOs during desiccation and stabilization of membrane phospholipids. Moreover, their high oligomeric length may positively impact protecting liposomes (Cacela and Hincha, 2006) and possibly act as a free radical scavenger (Nishizawa-Yokoi et al., 2008). Furthermore, several reports suggest that the accumulated RFOs under abiotic stress conditions function as osmolytes to maintain cell turgor and act as an antioxidant against reactive oxygen species (NishizawaYokoi et al., 2008; van den Ende and Valluru, 2008; BolouriMoghaddam et al., 2010; Stoyanova et al., 2011; van den Ende et al., 2011; Peshev et al., 2013).

Galactinol synthase (GolS) is a key enzyme that is involved in the biosynthesis of RFOs (Saravitz et al., 1987) and is known to be linked to abiotic stress (Sengupta et al., 2015). Therefore, genetically modulating the expression of GolS genes can provide much information about the involvement of RFOs in mediating response to abiotic stresses. These studies have been carried out mainly in Arabidopsis thaliana or tobacco (Nicotiana tabacum) plants, as they seem to elevate galactinol and raffinose content in response to abiotic stresses (Taji et al., 2002; Zhuo et al., 2013; Himuro et al., 2014; Shimosaka and Ozawa, 2015; Gu et al., 2016). Multiple isoforms of Gols have been identified from various plant species so far; each is synthesized under various circumstances of abiotic stresses. It has been found that out of seven identified GolS genes from Arabidopsis thaliana, AtGolS1 and AtGolS2 were induced by drought, salt, or heat stress. In contrast, AtGolS3 from the same genome were induced by cold stress (Taji et al., 2002). Over-expressing or knocking out these genes can be made use of for the study of RFOs physiology. Studies by Taji et al. (2002) and Panikulangara et al. (2004) showed that over-expression of these genes induced accumulation of galactinol ( $\mathrm{Gol}$ ), raffinose (Raf), and stachyose (Sta) and eventually improved the plant's tolerance level to drought, salinity, or cold stress. Panikulangara et al. (2004) also proved that AtGolS1 mutant plants fail to accumulate heat stress-induced Gol and Raf, indicating that AtGolS1 may be the crucial GolS isoform responsible for heat stress-induced Raf or Gol accumulation. However, a study by Peters et al. (2010) involving a double mutant; claimed that despite the improved accumulation of GolS1 in GolS2 mutants, 
they remain hypersensitive to water stress, exhibit rapid loss of water and lower enzymatic activity. Hence indicating they are drought hypersensitive. Such observations concerning the fact that Arabidopsis neither stores nor transports RFOs prove the involvement of various biosynthetic pathways that are supplied to by different GolS isoforms. Likewise, cold temperature tolerance was achieved by overexpressing the Medicago falcata Gols (MfGolS1) gene in tobacco (Zhuo et al., 2013).

Valluru and van den Ende (2011) explained the role of galactinol in signaling RFOs to mediate stress responses, including a signal in response to pathogen infection. Thus, evidencing the role of RFOs in defense against biotic stress. GolS induced the expression of defense-related genes such as PR1a, PR1b, and NtACS1 in tobacco upon Botrytis cinerea and Erwinia carotovora infection (Kim et al., 2008). Also, Gol induces the salicylic acid (SA) signaling upon pathogen infection and eventually turns on the PR1a gene expression to control disease progression (Couée et al., 2006). RFOs (mainly GolS and RafS) contain W-box cis-elements in their promotors, regulated by ABA-inducible WRKY (Wang et al., 2009). This suggests a possible role of RFOs in SA and ABA signaling under biotic and abiotic stresses. Figure 3, depicting the role of RFOs in plant health, including their role in seed germination, seed development, desiccation tolerance, biotic and abiotic stress tolerance.

\section{Seed Germination}

Raffinose family oligosaccharides accumulate over the period in all parts of developing seeds, including endosperm, embryo, and seed coat (Kuo et al., 1988; Horbowicz and Obendorf, 1994; Frias et al., 1999). But the level and class of RFOs deposition may vary between different tissues. These RFOs significantly impact seed germination, often protect the embryos from desiccation during seed maturation and improve the longevity of the seeds under adverse conditions (Peterbauer et al., 2002a,b). During the early stages of seed germination, RFOs are readily available and provide energy and carbon to the germinating seeds (Zhao et al., 2006).

\section{Desiccation Tolerance}

The seed germination process demands a lot of water; the water loss during seed germination is known as "desiccation." This may lead to membrane damage and the death of the embryo. Accumulation of non-reducing sugars such as sucrose and RFOs may prevent the desiccation process in seeds (Koster and Leopold, 1988), and many reports suggested the role of RFOs in desiccation tolerance (Blackman et al., 1992; Corbineau et al., 2000; Angelovici et al., 2010). There were two mechanisms reported where RFOs act in mitigating the desiccation process in seeds. The first mechanism is known as "water replacement," where the hydroxyl groups of RFOs can replace water molecules and maintain the hydrophilic interactions within the cell that are necessary for stabilizing native macromolecules and membrane structure during dehydration process (Koster, 1991). The second mechanism is called "vitrification." This is the state of a cell solution having very high viscosity due to loss of water. At this state, the cell solution has the properties of a plastic solid. It is accountable for warranting stability, preventing cellular collapse, and maintaining hydrogen bonding within the cell (Koster and Leopold, 1988; Koster, 1991; Martínez-Villaluenga et al., 2008; Angelovici et al., 2010). Pukacka et al. (2009) reported that the late embryogenesis abundant (LEA) proteins and small heat shock proteins (sHSP) along with RFOs are responsible for the vitrification state.

\section{ROLE OF RAFFINOSE FAMILY OLIGOSACCHARIDES IN HUMAN HEALTH}

Raffinose family oligosaccharides are ubiquitous in legume seeds (Minorsky, 2003), and they are composed of $\alpha$-(1,6)-galactosides linked to a sucrose unity (Cardoso et al., 2021). Humans and animals do not produce an $\alpha$-galactosidase enzyme to synthesize and digest the RFOs in the intestine (Minorsky, 2003; Mao et al., 2014). Therefore, RFOs escape the digestion process and get utilized by the gut microbes (bacteria) to synthesize byproducts like hydrogen $\left(\mathrm{H}_{2}\right)$, carbon dioxide $\left(\mathrm{CO}_{2}\right)$, and methane $\left(\mathrm{CH}_{4}\right)$. Thus, RFOs primarily cause flatulence in humans and animals (Naczk et al., 1997; Minorsky, 2003). Hence, RFOs are considered the single most deterring factor for the wide acceptance of legumes in human and animal diets (Delumen, 1992). Therefore, only a limited quantity of soybean meals was allowed in animal feeds to avoid flatulence and digestive problems in dogs (Canis familiaris), baby pigs (Sus scrofa), and chickens (Gallus domesticus) (Hartwig et al., 1997). The pharmaceutical company GlaxoSmithKline released a commercial product ${ }^{1}$ "Beano," which supplies $\alpha$-galactosidase and sucrase enzymes in the human body to hydrolyze RFOs mitigate the flatulence problem. Recently, the $\alpha$-galactosidase gene ( $g a l C$ ) was cloned from Aspergillus oryzae (YZ1) and expressed in Pichia pastoris for protein production, and galC effectively degraded the RFOs (primarily raffinose and stachyose) in soymilk (Wang et al., 2020). But recent studies have shown the benefit of RFOs in human health (Dinoto et al., 2006; Fernando et al., 2010; Takagi et al., 2016; Pacifici et al., 2017; Collins et al., 2018; Ose et al., 2018; Xu et al., 2018; Zartl et al., 2018; Amorim et al., 2020; Cardoso et al., 2021). Moreover, RFOs can be converted into prebiotic molecules using enzymes via catalytic transformations. For example, levansucrase can convert raffinose to melibiose and stachyose to mannotriose (Park et al., 2003; Xu et al., 2017; Jadaun et al., 2019).

Recent studies reported the prebiotic potential of the RFOs in human guts; they promoted the growth of beneficial bacterias such as Bifidobacteria and Lactobacilli and reduced the harmful bacterias present in the colon (Mao et al., 2014; Takagi et al., 2016; Ose et al., 2018; Zartl et al., 2018; Amorim et al., 2020). Apart from the beneficial effect on gut microbiota, RFOs administration improved the intestine microbial composition in healthy adults (Dinoto et al., 2006; Fernando et al., 2010), improved the growth of sturgeon hybrids (Xu et al., 2018), improved the Fe availability and intestinal brush border membrane functionality in Gallus

\footnotetext{
${ }^{1}$ www.beanogas.com
} 
gallus (Pacifici et al., 2017), and RFOs increased the number of Lactobacillus (beneficial bacteria) present in the vaginal microbiota (Collins et al., 2018). Many other biological activities of RFOs have been reported apart from the prebiotic potential, such as anti-allergic (Nagura et al., 2002; Watanabe et al., 2004), anti-obesity, anti-diabetic, and prevention of non-alcoholic fatty liver disease through inhibition of lipid accumulation (Muthukumaran et al., 2018), reduction of fecal ammonia and indole (Nagura et al., 1999; Elliott et al., 2017), cryoprotection (Elliott et al., 2017), and inhibition of Pseudomonas aeruginosa biofilm formation (Kim et al., 2016).

Lupin seeds have high RFOs compared to other pulses (Martínez-Villaluenga et al., 2005; Johnson et al., 2017). The extract from lupin seeds had positive effects on the survival of probiotic cultures in dairy products (Martínez-Villaluenga et al., 2006), and RFOs isolated from the novel plants Rehmannia glutinosa, used as food ingredients to prevent ROS-related liver damage (Dai et al., 2018). RFOs also reduced the severity of colon inflammation in mice (Zhang et al., 2013). Raffinose isolated from the rhizome of Costus speciosus inhibits lipid accumulation (Muthukumaran et al., 2018), and stachyose prevents ulcerative colitis in mice (He et al., 2020). RFOs are reported to have a therapeutic effect on curing cutaneous disorders ( $\mathrm{Na}$ et al., 2017). Largely, RFOs may have diverse applications in food (human), feed (animal), cosmetic, health (human, plant, and animal), and pharmaceutical, and received food for specified health uses (FOSHU) status in 2003 (Bailey, 2005), and widely consumed as a functional ingredient in Japan (Takakuwa et al., 2007). However, wider recognition in other parts of the world as functional foods is not yet reached.

\section{EMERGING RESEARCH ISSUES}

Raffinose family oligosaccharides could be exploited as functional foods. Its multi-functional benefits are still yet to be realized in human and animal well-being. RFOs positively affect the gut microbiota, large intestines, and colon health and could be used as therapeutic agents to reduce inflammation, diabetics, allergies, etc. RFOs are considered the prime suspect for flatulence in humans and animals. Hence, for the crops with high RFOs, especially grain legumes, adoption in the food and feed system is heavily impaired due to the flatulence problem. Therefore, we need to strike the right balance of RFO content in crops to promote them as functional foods. Still, the right concentration of RFOs needed for human well-being is the area to be explored further. Moreover, except Japan, other parts of the world have yet to approve RFOs as functional foods.

\section{REFERENCES}

Aguilera, Y., Martín-Cabrejas, M. A., Benítez, V., Mollá, E., López-Andréu, F. J., and Esteban, R. M. (2009). Changes in carbohydrate fraction during dehydration process of common legumes. J. Food Compos. Anal. 22, 678-683. doi: $10.1016 /$ j.jfca.2009.02.012

Alajaji, S. A., and El-Adawy, T. A. (2006). Nutritional composition of chickpea (Cicer arietinum L.) as affected by microwave cooking and other traditional
Achieving desirable sugar profiles without compromising yield, protein, oil, and other micronutrients in grain legumes is important to satisfy the changing dietary habits. A significant negative correlation was reported between protein content and RFOs in soybean (Hartwig et al., 1997; Bueno et al., 2018). But a significant positive correlation was reported between oil and RFO content in soybean (Patil et al., 2017; Bueno et al., 2018). We need to fine-tune the portion of protein, fat, sugar, and oil contents in grain legumes through breeding by developing genotypes with high yield and balanced nutrition. Recently, CRISPR knockouts helped reduce the RFO contents considerably in soybean, including the major RFO sugar stachyose, by $35 \%$. But raffinose content was increased to $42 \%$, and protein and fat contents were also increased (Le et al., 2020).

Future research must focus on mitigating the issues related to quality and soluble sugars in legumes. Sprouting was reported to reduce the RFO contents in seeds in various legumes (Åman, 1979; Raman et al., 2019). Reduction of myo-inositol level led to a drastic decrease of galactinol and RFO levels in mutant soybean seeds (Hitz et al., 2002). Mutations in myoinositol phosphate synthase may affect RFO concentration, and they are potential targets for modifications of RFO content in plants. There is an urgent need to understand the relationship between galactinol synthase activity and the accumulation of RFO in plant tissues, which would be another exciting area of research. Finally, finetuning the optimum level of RFOs in crop plants to reap the benefits of RFOs in plant and human health is yet to be explored further.

\section{AUTHOR CONTRIBUTIONS}

DE conceived the need for the review. DE, KR, LV, SS, NT, NE, and $\mathrm{BR}$ jointly wrote the first draft. JR, WW, AF, KC, MT, RV, and SC edited the first draft. AS and AKS edited and provided guidance to finish the final draft for submission. All authors read, edited and approved the manuscript.

\section{ACKNOWLEDGMENTS}

We thank "Biorender.com" for providing tools to create a picture of the functional aspects of RFOs in plant health, and Ms. Akhila Jabeen for creating reference library during the initial period of the manuscript writing process. The open access publication fees for this article were covered by the Iowa State University Library.

cooking methods. J. Food Compos. Anal. 19, 806-812. doi: 10.1016/j.jfca.2006. 03.015

Åman, P. (1979). Carbohydrates in raw and germinated seeds from mung bean and chick pea. J. Sci. Food Agric. 30, 869-875. doi: 10.1002/jsfa.2740300907

Amorim, C., Silvério, S. C., Cardoso, B. B., Alves, J. I., Pereira, M. A., and Rodrigues, L. R. (2020). In vitro fermentation of raffinose to unravel its potential as prebiotic ingredient. LWT 126:109322. doi: 10.1016/j.lwt.2020. 109322 
Andersen, K. E., Bjergegaard, C., Møller, P., Sørensen, J. C., and Sørensen, H. (2005). Compositional Variations for $\alpha$-Galactosides in Different Species of Leguminosae, Brassicaceae, and Barley: a Chemotaxonomic Study Based on Chemometrics and High-Performance Capillary Electrophoresis. J. Agric. Food Chem. 53, 5809-5817. doi: 10.1021/jf040471v

Angelovici, R., Galili, G., Fernie, A. R., and Fait, A. (2010). Seed desiccation: a bridge between maturation and germination. Trends Plant Sci. 15, 211-218. doi: 10.1016/j.tplants.2010.01.003

Asif, M. I., Wani, S. A., Lone, A. A., Dar, Z. A., and Nehvi, F. A. (2013). "Breeding for Quality Traits in Grain Legumes," in Conventional and Non-Conventional Interventions in Crop Improvement, eds C. P. Malik, G. Sanghera, and S. H. Wani.(New Delhi: M D Publishers). Available online at: https://www.researchgate.net/publication/257645622_Breeding_for_ Quality_Traits_in_Grain_Legumes (accessed February 04, 2022).

Bachmann, M., and Keller, F. (1995). Metabolism of the Raffinose Family Oligosaccharides in Leaves of Ajuga reptans L. (Inter- and Intracellular Compartmentation). Plant Physiol. 109, 991-998. doi: 10.1104/pp.109.3.991

Bachmann, M., Matile, P., and Keller, F. (1994). Metabolism of the Raffinose Family Oligosaccharides in Leaves of Ajuga reptans L. (Cold Acclimation, Translocation, and Sink to Source Transition: discovery of Chain Elongation Enzyme). Plant Physiol. 105, 1335-1345. doi: 10.1104/pp.105.4.1335

Bailey, R. (2005). "Functional Foods in Japan: Foshu ('foods for Specified Health Uses') and 'foods with Nutrient Function Claims', in Regulation of Functional Foods and Nutraceuticals, ed. C. M. Hasler (Oxford: Blackwell Publishing Ltd). doi: 10.1002/9780470277676.ch15

Beebe, D. U., and Turgeon, R. (1992). Localization of galactinol, raffinose, and stachyose synthesis in Cucurbita pepo leaves. Planta 188, 354-361. doi: 10.1007/ BF00192802

Bilyeu, K. D., and Wiebold, W. J. (2016). Environmental Stability of Seed Carbohydrate Profiles in Soybeans Containing Different Alleles of the Raffinose Synthase 2 (RS2) Gene. J. Agric. Food Chem. 64, 1071-1078. doi: 10.1021/acs. jafc.5b04779

Blackman, S. A., Obendorf, R. L., and Leopold, A. C. (1992). Maturation Proteins and Sugars in Desiccation Tolerance of Developing Soybean Seeds. Plant Physiol. 100, 225-230. doi: 10.1104/pp.100.1.225

Blöchl, A., March, G. G., Sourdioux, M., Peterbauer, T., and Richter, A. (2005). Induction of raffinose oligosaccharide biosynthesis by abscisic acid in somatic embryos of alfalfa (Medicago sativa L.). Plant Sci. 168, 1075-1082. doi: 10.1016/ j.plantsci.2004.12.004

Blöchl, A., Peterbauer, T., and Richter, A. (2007). Inhibition of raffinose oligosaccharide breakdown delays germination of pea seeds. J. Plant Physiol. 164, 1093-1096. doi: 10.1016/j.jplph.2006.10.010

Bock, C., Ray, H., and Georges, F. (2009). Down-regulation of galactinol synthesis in oilseed Brassica napus leads to significant reduction of antinutritional oligosaccharides. Botany 87, 597-603. doi: 10.1139/B09-037

Bolouri-Moghaddam, M. R., le Roy, K., Xiang, L., Rolland, F., and van den Ende, W. (2010). Sugar signalling and antioxidant network connections in plant cells. FEBS J. 277, 2022-2037. doi: 10.1111/j.1742-4658.2010.07633.x

Bueno, R. D., Borges, L. L., Good God, P. I. V., Piovesan, N. D., Teixeira, A. I., Cruz, C. D., et al. (2018). Quantification of anti-nutritional factors and their correlations with protein and oil in soybeans. An. Acad. Bras. Cienc. 90, 205-217. doi: 10.1590/0001-3765201820140465

Cacela, C., and Hincha, D. K. (2006). Monosaccharide composition, chain length and linkage type influence the interactions of oligosaccharides with dry phosphatidylcholine membranes. Biochim. Biophys. Acta Biomembr. 1758, 680691. doi: 10.1016/j.bbamem.2006.04.005

Calloway, D. H., and Murphy, E. L. (1968). Use of expired air to measure intestinal gas formation. Ann. N. Y. Acad. Sci. 150, 82-95. doi: 10.1111/j.1749-6632.1968. tb19034.x

Cardoso, B. B., Amorim, C., Silvério, S. C., and Rodrigues, L. R. (2021). "Novel and emerging prebiotics: advances and opportunities. Adv. Food Nutr. Res. 95, 41-95. doi: 10.1016/bs.afnr.2020.08.001

Collins, S. L., McMillan, A., Seney, S., van der Veer, C., Kort, R., Sumarah, M. W., et al. (2018). Promising Prebiotic Candidate Established by Evaluation of Lactitol, Lactulose, Raffinose, and Oligofructose for Maintenance of a Lactobacillus-Dominated Vaginal Microbiota. Appl. Environ. Microbiol. 84, e2200-e2217. doi: 10.1128/AEM.02200-17

Comfort, D. A., Bobrov, K. S., Ivanen, D. R., Shabalin, K. A., Harris, J. M., Kulminskaya, A. A., et al. (2007). Biochemical Analysis of Thermotoga maritima GH36 $\alpha$-Galactosidase (TmGalA) Confirms the Mechanistic Commonality of Clan GH-D Glycoside Hydrolases. Biochemistry 46, 33193330. doi: 10.1021/bi061521n

Corbineau, F., Picard, M. A., Fougereux, J.-A., Ladonne, F., and Côme, D. (2000). Effects of dehydration conditions on desiccation tolerance of developing pea seeds as related to oligosaccharide content and cell membrane properties. Seed Sci. Res. 10, 329-339. doi: 10.1017/S0960258500000374

Couée, I., Sulmon, C., Gouesbet, G., and El Amrani, A. (2006). Involvement of soluble sugars in reactive oxygen species balance and responses to oxidative stress in plants. J. Exp. Bot. 57, 449-459. doi: 10.1093/jxb/erj027

Dai, Z., Feng, S., Liu, A., Wang, H., Zeng, X., and Yang, C. S. (2018). Anti-inflammatory effects of newly synthesized $\alpha$-galacto-oligosaccharides on dextran sulfate sodium-induced colitis in C57BL/6J mice. Food Res. Int. 109, 350-357. doi: 10.1016/j.foodres.2018.04.054

Delumen, B. O. (1992). Molecular strategies to improve protein-quality and reduce flatulence in legumes - a review. Food Struct. 11, 33-46.

Dibofori, A., Okoh, P., and Onigbinde, A. (1994). Effect of germination on the cyanide and oligosaccharide content of lima beans (Phaseolus lunatus). Food Chem. 51, 133-156. doi: 10.1016/0308-8146(94)90246-1

Dierking, E. C., and Bilyeu, K. D. (2008). Association of a Soybean Raffinose Synthase Gene with Low Raffinose and Stachyose Seed Phenotype. Plant Genome 1:135. doi: 10.3835/plantgenome2008.06.0321

Dierking, E. C., and Bilyeu, K. D. (2009). Raffinose and stachyose metabolism are not required for efficient soybean seed germination. J. Plant Physiol. 166, 1329-1335. doi: 10.1016/j.jplph.2009.01.008

Dinant, S., and Lemoine, R. (2010). The phloem pathway: new issues and old debates. C. R. Biol. 333, 307-319. doi: 10.1016/j.crvi.2010.01.006

Dinoto, A., Marques, T. M., Sakamoto, K., Fukiya, S., Watanabe, J., Ito, S., et al. (2006). Population Dynamics of Bifidobacterium Species in Human Feces during Raffinose Administration Monitored by Fluorescence In Situ Hybridization-Flow Cytometry. Appl. Environ. Microbiol. 72, 7739-7747. doi: 10.1128/AEM.01777-06

Dobrenel, T., Marchive, C., Azzopardi, M., Clément, G., Moreau, M., Sormani, R., et al. (2013). ). Sugar metabolism and the plant target of rapamycin kinase: a sweet operaTOR?. Front. Plant Sci. 4:93. doi: $10.3389 /$ fpls.2013.00093

Egbe, I. A., and Akinyele, I. O. (1990). Effect of cooking on the antinutritional factors of lima beans (Phaseolus lunatus). Food Chem. 35, 81-87. doi: 10.1016/ 0308-8146(90)90022-V

Elliott, G. D., Wang, S., and Fuller, B. J. (2017). Cryoprotectants: a review of the actions and applications of cryoprotective solutes that modulate cell recovery from ultra-low temperatures. Cryobiology 76, 74-91. doi: 10.1016/j.cryobiol. 2017.04.004

Farrant, J. M. (2007). "Mechanisms of Desiccation Tolerance in Angiosperm Resurrection Plants," in Plant Desiccation Tolerance, eds M. A. Jenks and A. J. Wood (Oxford: Blackwell Publishing Ltd), doi: 10.1002/9780470376 881.ch3

Fernando, W., Hill, J., Zello, G., Tyler, R., Dahl, W., and van Kessel, A. (2010). Diets supplemented with chickpea or its main oligosaccharide component raffinose modify faecal microbial composition in healthy adults. Benef. Microbes 1, 97-207. doi: 10.3920/BM2009.0027

French, D. (1954). The Raffinose Family of Oligosaccharides. New York: Academic Press.

Frias, J., Bakhsh, A., Jones, D. A., Arthur, A. E., Vidal-Valverde, C., Rhodes, M. J. C., et al. (1999). Genetic analysis of the raffinose oligosaccharide pathway in lentil seeds. J. Exp. Bot. 50, 469-476. doi: 10.1093/jxb/50.333.469

Frias, J., Vidal-Valverde, C., Bakhsh, A., Arthur, A. E., and Hedley, C. (1994). An Assessment of Variation for Nutritional and Non-nutritional Carbohydrates in Lentil Seeds (Lens culinaris). Plant Breed. 113, 170-173. doi: 10.1111/j.14390523.1994.tb00719.x

Fridjonsson, O., Watzlawick, H., Gehweiler, A., Rohrhirsch, T., and Mattes, R. (1999). Cloning of the Gene Encoding a Novel Thermostable $\alpha$-Galactosidase from Thermus brockianus ITI360. Appl. Environ. Microbiol. 65, 3955-3963. doi: 10.1128/AEM.65.9.3955-3963.1999

Gangl, R., and Tenhaken, R. (2016). Raffinose family oligosaccharides act as galactose stores in seeds and are required for rapid germination of Arabidopsis in the dark. Front. Plant Sci. 7:1115. doi: 10.3389/fpls.2016.01115

Gangola, M. P., Jaiswal, S., Kannan, U., Gaur, P. M., Båga, M., and Chibbar, R. N. (2016). Galactinol synthase enzyme activity influences raffinose family 
oligosaccharides (RFO) accumulation in developing chickpea (Cicer arietinum L.) seeds. Phytochemistry 125, 88-98. doi: 10.1016/j.phytochem.2016.02.009

Garro, M. S., de Giori, G. S., de Valdez, G. F., and Oliver, G. (1993). Characterization of alpha-galactosidase from Lactobacillus fermentum. J. Appl. Bacteriol. 75, 485-488. doi: 10.1111/j.1365-2672.1993.tb02805.x

Giannoccaro, E., Wang, Y.-J., and Chen, P. (2008). Comparison of two HPLC systems and an enzymatic method for quantification of soybean sugars. Food Chem. 106, 324-330. doi: 10.1016/j.foodchem.2007.04.065

Gilbert, G. A., Wilson, C., and Madore, M. A. (1997). Root-Zone Salinity Alters Raffinose Oligosaccharide Metabolism and Transport in Coleus. Plant Physiol. 115, 1267-1276. doi: 10.1104/pp.115.3.1267

Gote, M. M., Khan, M. I., Gokhale, D. V., Bastawde, K. B., and Khire, J. M. (2006). Purification, characterization and substrate specificity of thermostable $\alpha$ galactosidase from Bacillus stearothermophilus (NCIM-5146). Process Biochem. 41, 1311-1317. doi: 10.1016/j.procbio.2006.01.003

Gote, M., Umalkar, H., Khan, I., and Khire, J. (2004). Thermostable $\alpha$-galactosidase from Bacillus stearothermophilus (NCIM 5146) and its application in the removal of flatulence causing factors from soymilk. Process Biochem. 39, 17231729. doi: 10.1016/j.procbio.2003.07.008

Grieshop, C. M., Kadzere, C. T., Clapper, G. M., Flickinger, E. A., Bauer, L. L., Frazier, R. L., et al. (2003). Chemical and Nutritional Characteristics of United States Soybeans and Soybean Meals. J. Agric. Food Chem. 51, 7684-7691. doi: $10.1021 / \mathrm{jf} 034690 \mathrm{c}$

Gu, L., Zhang, Y., Zhang, M., Li, T., Dirk, L. M. A., Downie, B., et al. (2016). ZmGOLS2, a target of transcription factor ZmDREB2A, offers similar protection against abiotic stress as ZmDREB2A. Plant Mol. Biol. 90, 157-170. doi: $10.1007 / \mathrm{s} 11103-015-0403-1$

Gupta, Y. P. (1987). Anti-nutritional and toxic factors in food legumes: a review. Plant Foods Hum. Nutr. 37, 201-228. doi: 10.1007/BF01091786

Hagely, K. B., Jo, H., Kim, J.-H., Hudson, K. A., and Bilyeu, K. (2020). Molecularassisted breeding for improved carbohydrate profiles in soybean seed. Theor. Appl. Genet. 133, 1189-1200. doi: 10.1007/s00122-020-03541-z.

Han, I. H., and Baik, B.-K. (2006). Oligosaccharide Content and Composition of Legumes and Their Reduction by Soaking, Cooking, Ultrasound, and High Hydrostatic Pressure. Cereal Chem. J. 83, 428-433. doi: 10.1094/CC-83-0428

Han, Q., Qi, J., Hao, G., Zhang, C., Wang, C., Dirk, L. M. A., et al. (2019). ZmDREB1A Regulates RAFFINOSE SYNTHASE Controlling Raffinose Accumulation and Plant Chilling Stress Tolerance in Maize. Plant Cell Physiol. 61, 331-341. doi: 10.1093/pcp/pcz200

Hartwig, E. E., Kuo, T. M., and Kenty, M. M. (1997). Seed Protein and its Relationship to Soluble Sugars in Soybean. Crop Sci. 37, 770-773. doi: 10.2135/ cropsci1997.0011183X003700030013x

He, L., Zhang, F., Jian, Z., Sun, J., Chen, J., Liapao, V., et al. (2020). Stachyose modulates gut microbiota and alleviates dextran sulfate sodium-induced acute colitis in mice. Saudi J. Gastroenterol. 26, 153-159. doi: 10.4103/sjg.SJG_580_19

Himuro, Y., Ishiyama, K., Mori, F., Gondo, T., Takahashi, F., Shinozaki, K., et al. (2014). Arabidopsis galactinol synthase AtGolS2 improves drought tolerance in the monocot model Brachypodium distachyon. J. Plant Physiol. 171, 1127-1131. doi: 10.1016/j.jplph.2014.04.007

Hincha, D. K., Zuther, E., and Heyer, A. G. (2003). The preservation of liposomes by raffinose family oligosaccharides during drying is mediated by effects on fusion and lipid phase transitions. Biochim. Biophys. Acta Biomembr. 1612, 172-177. doi: 10.1016/S0005-2736(03)00116-0

Hitz, W. D., Carlson, T. J., Kerr, P. S., and Sebastian, S. A. (2002). Biochemical and Molecular Characterization of a Mutation That Confers a Decreased Raffinosaccharide and Phytic Acid Phenotype on Soybean Seeds. Plant Physiol. 128, 650-660. doi: 10.1104/pp.010585

Horbowicz, M., and Obendorf, R. L. (1994). Seed desiccation tolerance and storability: dependence on flatulence-producing oligosaccharides and cyclitols-review and survey. Seed Sci. Res. 4, 385-405. doi: 10.1017/ S0960258500002440

Hou, A., Chen, P., Alloatti, J., Li, D., Mozzoni, L., Zhang, B., et al. (2009a). Genetic Variability of Seed Sugar Content in Worldwide Soybean Germplasm Collections. Crop Sci. 49, 903-912. doi: 10.2135/cropsci2008.05.0256

Hou, A., Chen, P., Shi, A., Zhang, B., and Wang, Y.-J. (2009b). Sugar Variation in Soybean Seed Assessed with a Rapid Extraction and Quantification Method. Int. J. Agron. 2009, 1-8. doi: 10.1155/2009/484571
Huang, Y., Zhang, H., Ben, P., Duan, Y., Lu, M., Li, Z., et al. (2018). Characterization of a novel GH36 $\alpha$-galactosidase from Bacillus megaterium and its application in degradation of raffinose family oligosaccharides. Int. J. Biol. Macromol. 108, 98-104. doi: 10.1016/j.ijbiomac.2017.11.154

Huynh, K. K., Gershenzon, E., and Grinstein, S. (2008). Cholesterol Accumulation by Macrophages Impairs Phagosome Maturation. J. Biol. Chem. 283, 3574535755. doi: $10.1074 / \mathrm{jbc}$.M806232200

Hymowitz, T., and Collins, F. I. (1974). Variability of Sugar Content in Seed of Glycine max (L.) Merrill and G. soja Sieb. and Zucc. Agron. J. 66, 239-240. doi: 10.2134/agronj1974.00021962006600020017x

Jadaun, J. S., Narnoliya, L. K., Agarwal, N., and Singh, S. P. (2019). Catalytic biosynthesis of levan and short-chain fructooligosaccharides from sucrosecontaining feedstocks by employing the levansucrase from Leuconostoc mesenteroides MTCC10508. Int. J. Biol. Macromol. 127, 486-495. doi: 10.1016/ j.ijbiomac.2019.01.070

Johnson, N., Boatwright, J. L., Bridges, W., Thavarajah, P., Kumar, S., Shipe, E., et al. (2021). Genome-wide association mapping of lentil (Lens culinaris Medikus) prebiotic carbohydrates toward improved human health and crop stress tolerance. Sci. Rep. 11:13926. doi: 10.1038/s41598-021-93475-3

Johnson, S. K., Clements, J., Villarino, C. B. J., and Coorey, R. (2017). "Lupins: Their Unique Nutritional and Health-Promoting Attributes," in Gluten-Free Ancient Grains, eds J. R. N. Taylor and J. M. Awika (Amsterdam: Elsevier). doi: 10.1016/B978-0-08-100866-9.00008-X

Jones, D. A., DuPont, M. S., Ambrose, M. J., Frias, J., and Hedley, C. L. (1999). The discovery of compositional variation for the raffinose family of oligosaccharides in pea seeds. Seed Sci. Res. 9, 305-310. doi: 10.1017/S0960258599000318

Jood, S., Mehta, U., Bhat, C. M., and Singh, R. (1985). Effect of Processing on Flatus-Producing Factors in Legumes. J. Agric. Food Chem. 33, 268-271. doi: $10.1021 /$ jf00062a028

Kandler, O., and Hopf, H. (1982). "Oligosaccharides Based on Sucrose (Sucrosyl Oligosaccharides)," in Plant Carbohydrates I, eds F. A. Loewus and W. Tanner (Berlin: Springer), doi: 10.1007/978-3-642-68275-9_8

Kannan, U., Sharma, R., Gangola, M. P., Sari, N., and Chibbar, R. N. (2018). Improving Grain Quality in Pulses: strategies to Reduce Raffinose Family Oligosaccharides in Seeds. Ekin J. Crop Breed. Genet. 44, 70-88.

Katrolia, P., Rajashekhara, E., Yan, Q., and Jiang, Z. (2014). Biotechnological potential of microbial $\alpha$-galactosidases. Crit. Rev. Biotechnol. 34, 307-317. doi: 10.3109/07388551.2013.794124

Keller, F., and Pharr, D. M. (1996). "Metabolism of carbohydrates in sinks and sources: galactosyl-sucrose oligosaccharides," in Photoassimilate distribution in plants and crops, eds E. Zamski and A. A. Schaffer (Milton Park: Taylor \& Francis), 115-184.

Kennedy, I. R., Mwandemele, O. D., and McWhirter, K. S. (1985). Estimation of sucrose, raffinose and stachyose in soybean seeds. Food Chem. 17, 85-93. doi: 10.1016/0308-8146(85)90077-9

Kim, H.-S., Cha, E., Kim, Y., Jeon, Y. H., Olson, B. H., Byun, Y., et al. (2016). Raffinose, a plant galactoside, inhibits Pseudomonas aeruginosa biofilm formation via binding to LecA and decreasing cellular cyclic diguanylate levels. Sci. Rep. 6:25318. doi: 10.1038/srep25318

Kim, M. S., Cho, S. M., Kang, E. Y., Im, Y. J., Hwangbo, H., Kim, Y. C., et al. (2008). Galactinol is a Signaling Component of the Induced Systemic Resistance Caused by Pseudomonas chlororaphis O6 Root Colonization. Mol. Plant Microbe Interact. 21, 1643-1653. doi: 10.1094/MPMI-21-12-1643

Koster, K. L. (1991). Glass Formation and Desiccation Tolerance in Seeds. Plant Physiol. 96, 302-304. doi: 10.1104/pp.96.1.302

Koster, K. L., and Leopold, A. C. (1988). Sugars and Desiccation Tolerance in Seeds. Plant Physiol. 88, 829-832. doi: 10.1104/pp.88.3.829

Kumar, V., Rani, A., Goyal, L., Dixit, A. K., Manjaya, J. G., Dev, J., et al. (2010). Sucrose and Raffinose Family Oligosaccharides (RFOs) in Soybean Seeds As Influenced by Genotype and Growing Location. J. Agric. Food Chem. 58, 5081-5085. doi: 10.1021/jf903141s

Kuo, T. M., VanMiddlesworth, J. F., and Wolf, W. J. (1988). Content of raffinose oligosaccharides and sucrose in various plant seeds. J. Agric. Food Chem. 36, 32-36. doi: 10.1021/jf00079a008

Lahuta, L. B., Goszczynska, J., and Horbowicz, M. (2010). Seed $\alpha$-D-galactosides of selected Vicia species and enzymes involved in their biosynthesis. Acta Biol. Crac. Ser. Bot. 52, 27-35. 
Lattanzio, V., Bianco, V. V., Miccolis, V., and Linsalata, V. (1986). Mono- and oligosaccharides in fifteen Vicia faba L. cultivars. Food Chem. 22, 17-25. doi: 10.1016/0308-8146(86)90004-X

Le, H., Nguyen, N. H., Ta, D. T., Le, T. N. T., Bui, T. P., Le, N. T., et al. (2020). CRISPR/Cas9-Mediated Knockout of Galactinol Synthase-Encoding Genes Reduces Raffinose Family Oligosaccharide Levels in Soybean Seeds. Front. Plant Sci. 11:612942. doi: 10.3389/fpls.2020.612942

Lee, A., Choi, K.-H., Yoon, D., Kim, S., and Cha, J. (2017). Characterization of a thermostable glycoside hydrolase family $36 \alpha$-galactosidase from Caldicellulosiruptor bescii. J. Biosci. Bioeng. 124, 289-295. doi: 10.1016/j.jbiosc. 2017.04.011

Lee, E. J., Matsumura, Y., Soga, K., Hoson, T., and Koizumi, N. (2007). Glycosyl hydrolases of cell wall are induced by sugar starvation in Arabidopsis. Plant Cell Physiol. 48, 405-413. doi: 10.1093/pcp/pcm009

Lineback, D. R., and Ke, C. H. (1975). Starches and low-molecular-weight carbohydrates from chick pea and horse bean flours. Cereal Chem. 52, 334-347.

Loewus, F. A., and Murthy, P. P. N. (2000). myo-Inositol metabolism in plants. Plant Sci. 150, 1-19. doi: 10.1016/S0168-9452(99)00150-8

Mansour, E. H., and Khalil, A. H. (1998). Reduction of raffinose oligosaccharides in chickpea (Cicer arietinum) flour by crude extracellular fungal $\alpha$-galactosidase. J. Sci. Food Agric. 78, 175-181.

Mao, B., Li, D., Zhao, J., Liu, X., Gu, Z., Chen, Y. Q., et al. (2014). In Vitro Fermentation of Lactulose by Human Gut Bacteria. J. Agric. Food Chem. 62, 10970-10977. doi: 10.1021/jf503484d

Martínez-Villaluenga, C., Frías, J., and Vidal-Valverde, C. (2005). Raffinose family oligosaccharides and sucrose contents in 13 Spanish lupin cultivars. Food Chem. 91, 645-649. doi: 10.1016/j.foodchem.2004.06.034

Martínez-Villaluenga, C., Frias, J., and Vidal-Valverde, C. (2008). AlphaGalactosides: antinutritional Factors or Functional Ingredients?. Crit. Rev. Food Sci. Nutr. 48, 301-316. doi: 10.1080/10408390701326243

Martínez-Villaluenga, C., Frías, J., Gómez, R., and Vidal-Valverde, C. (2006). Influence of addition of raffinose family oligosaccharides on probiotic survival in fermented milk during refrigerated storage. Int. Dairy J. 16, 768-774. doi: 10.1016/j.idairyj.2005.08.002

Minorsky, P. V. (2003). The Hot and the Classic. Plant Physiol. 131, 25-26. doi: $10.1104 /$ pp.900066

Mubarak, A. E. (2005). Nutritional composition and antinutritional factors of mung bean seeds (Phaseolus aureus) as affected by some home traditional processes. Food Chem. 89, 489-495. doi: 10.1016/j.foodchem.2004.01.007

Mulimani, V. H., and Ramalingam. (1997). Enzymatic degradation of raffinose family sugars in chickpea flour. World J. Microbio. Biotechnol. 13, 583-585. doi: 10.1023/A:1018529812482

Muthukumaran, P., Thiyagarajan, G., Arun Babu, R., and Lakshmi, B. S. (2018). Raffinose from Costus speciosus attenuates lipid synthesis through modulation of PPARs/SREBP1c and improves insulin sensitivity through PI3K/AKT. Chem. Biol. Interact. 284, 80-89. doi: 10.1016/j.cbi.2018.02.011

Na, T.-Y., Kim, G.-H., Oh, H.-J., Lee, M.-H., Han, Y.-H., Kim, K. T., et al. (2017). The trisaccharide raffinose modulates epidermal differentiation through activation of liver X receptor. Sci. Rep. 7:43823. doi: 10.1038/srep43823

Naczk, M., Amarowicz, R., and Shahidi, F. (1997). $\alpha$-Galactosides of Sucrose in Foods: Composition, Flatulence-Causing Effects, and Removal. ACS Symp. Ser. 662, 127-151. doi: 10.1021/bk-1997-0662.ch008

Nagura, T., Hachimura, S., Hashiguchi, M., Ueda, Y., Kanno, T., Kikuchi, H., et al. (2002). Suppressive effect of dietary raffinose on T-helper 2 cell-mediated immunity. Br. J. Nutr. 88, 421-426. doi: 10.1079/BJN2002666

Nagura, T., Muraguchi, H., Uchino, K., Aritsuka, T., and Benno, Y. (1999). Effects of ingestion of raffinose-rich soup on the fecal flora and daily defecation in humans. J. Intest. Microbiol. 13, 1-7.

Nakai, H., Baumann, M. J., Petersen, B. O., Westphal, Y., Hachem, M. A., Dilokpimol, A., et al. (2010). Aspergillus nidulans $\alpha$-galactosidase of glycoside hydrolase family 36 catalyses the formation of $\alpha$-galacto-oligosaccharides by transglycosylation. FEBS J. 277, 3538-3551. doi: 10.1111/j.1742-4658.2010. 07763.x

Nishizawa, A., Yabuta, Y., and Shigeoka, S. (2008). Galactinol and Raffinose Constitute a Novel Function to Protect Plants from Oxidative Damage. Plant Physiol. 147, 1251-1263. doi: 10.1104/pp.108.122465

Nishizawa-Yokoi, A., Yabuta, Y., and Shigeoka, S. (2008). The contribution of carbohydrates including raffinose family oligosaccharides and sugar alcohols to protection of plant cells from oxidative damage. Plant Signal. Behav. 3, 1016-1018. doi: 10.4161/psb.6738

Obendorf, R. L., and Górecki, R. J. (2012). Soluble carbohydrates in legume seeds. Seed Sci. Res. 22, 219-242. doi: 10.1017/S0960258512000104

Oboh, H. A., Muzquiz, M., Burbano, C., Cuadrado, C., Pedrosa, M. M., Ayet, G., et al. (2000). Effect of soaking, cooking and germination on the oligosaccharide content of selected Nigerian legume seeds. Plant Foods Hum. Nutr. 55, 97-110. doi: 10.1023/A:1008133531726

Okada, M., and Ye, K. (2009). Nuclear phosphoinositide signaling regulates messenger RNA export. RNA Biol. 6, 12-16. doi: 10.4161/rna.6.1.7439

Ose, R., Hirano, K., Maeno, S., Nakagawa, J., Salminen, S., Tochio, T., et al. (2018). The ability of human intestinal anaerobes to metabolize different oligosaccharides: novel means for microbiota modulation?. Anaerobe 51, 110 119. doi: 10.1016/j.anaerobe.2018.04.018

Pacifici, S., Song, J., Zhang, C., Wang, Q., Glahn, R., Kolba, N., et al. (2017). Intra Amniotic Administration of Raffinose and Stachyose Affects the Intestinal Brush Border Functionality and Alters Gut Microflora Populations. Nutrients 9:304. doi: 10.3390/nu9030304

Panikulangara, T. J., Eggers-Schumacher, G., Wunderlich, M., Stransky, H., and Schöffl, F. (2004). Galactinol synthase1. A Novel Heat Shock Factor Target Gene Responsible for Heat-Induced Synthesis of Raffinose Family Oligosaccharides in Arabidopsis. Plant Physiol. 136, 3148-3158. doi: 10.1104/pp.104.042606

Park, H.-E., Park, N. H., Kim, M.-J., Lee, T. H., Lee, H. G., Yang, J.-Y., et al. (2003). Enzymatic synthesis of fructosyl oligosaccharides by levansucrase from Microbacterium laevaniformans ATCC 15953. Enzyme Microb. Technol. 32, 820-827. doi: 10.1016/S0141-0229(03)00062-0

Patil, G., Mian, R., Vuong, T., Pantalone, V., Song, Q., Chen, P., et al. (2017). Molecular mapping and genomics of soybean seed protein: a review and perspective for the future. Theor. Appl. Genet. 130, 1975-1991. doi: 10.1007/ s00122-017-2955-8

Pennycooke, J. C., Jones, M. L., and Stushnoff, C. (2003). Down-Regulating $\alpha$-Galactosidase Enhances Freezing Tolerance in Transgenic Petunia. Plant Physiol. 133, 901-909. doi: 10.1104/pp.103.024554

Peshev, D., Vergauwen, R., Moglia, A., Hideg, É, and van den Ende, W. (2013). Towards understanding vacuolar antioxidant mechanisms: a role for fructans?. J. Exp. Bot. 64, 1025-1038. doi: 10.1093/jxb/ers377

Peterbauer, T., and Richter, A. (2001). Biochemistry and physiology of raffinose family oligosaccharides and galactosyl cyclitols in seeds. Seed Sci. Res. 11, 185-197. doi: 10.1079/SSR200175

Peterbauer, T., Karner, U., Mucha, J., Mach, L., Jones, D. A., Hedley, C. L., et al. (2003). Enzymatic control of the accumulation of verbascose in pea seeds. Plant Cell Environ. 26, 1385-1391. doi: 10.1046/j.0016-8025.2003.01063.x

Peterbauer, T., Mach, L., Mucha, J., and Richter, A. (2002a). Functional expression of a cDNA encoding pea (Pisum sativum L.) raffinose synthase, partial purification of the enzyme from maturing seeds, and steady-state kinetic analysis of raffinose synthesis. Planta 215, 839-846. doi: 10.1007/s00425-0020804-7

Peterbauer, T., Mucha, J., Mach, L., and Richter, A. (2002b). Chain Elongation of Raffinose in Pea Seeds. J. Biol. Chem. 277, 194-200. doi: 10.1074/jbc. M109734200

Peters, S., and Keller, F. (2009). Frost tolerance in excised leaves of the common bugle (Ajuga reptans L.) correlates positively with the concentrations of raffinose family oligosaccharides (RFOs). Plant Cell Environ. 32, 1099-1107. doi: 10.1111/j.1365-3040.2009.01991.x

Peters, S., Egert, A., Stieger, B., and Keller, F. (2010). Functional Identification of Arabidopsis ATSIP2 (At3g57520) as an Alkaline-Galactosidase with a Substrate Specificity for Raffinose and an Apparent Sink-Specific Expression Pattern. Plant Cell Physiol.51, 1815-1819. doi: 10.1093/pcp/pcq127

Polowick, P. L., Baliski, D. S., Bock, C., Ray, H., and Georges, F. (2009). Overexpression of $\alpha$-galactosidase in pea seeds to reduce raffinose oligosaccharide content. Botany 87, 526-532. doi: 10.1139/B09-020

Pukacka, S., Ratajczak, E., and Kalemba, E. (2009). Non-reducing sugar levels in beech (Fagus sylvatica) seeds as related to withstanding desiccation and storage. J. Plant Physiol. 166, 1381-1390. doi: 10.1016/j.jplph.2009.02.013

Qiu, D., Vuong, T., Valliyodan, B., Shi, H., Guo, B., Shannon, J. G., et al. (2015). Identification and characterization of a stachyose synthase gene controlling reduced stachyose content in soybean. Theor. Appl. Genet. 128, 2167-2176. doi: $10.1007 / \mathrm{s} 00122-015-2575-0$ 
Raja, S., Cheema, H. M. N., Babar, S., Khan, A. A., Murtaza, G., and Aslam, U. (2015). Socio-economic background of wastewater irrigation and bioaccumulation of heavy metals in crops and vegetables. Agric. Water Manag. 158, 26-34. doi: 10.1016/j.agwat.2015.04.004

Ramadoss, B. R., Balraj, R., Agasimani, S., Elango, D., Venkatesan, T., Jutti, R. K. B., et al. (2015). Determination of oligosaccharide fraction in a worldwide germplasm collection of chickpea (Cicer arietinum L.) using high performance liquid chromatography. Aust. J. Crop Sci. 9, 605-613.

Raman, M., Saiprasad, G. V. S., and Madhavakrishna, K. (2019). From seed to feed: assessment and alleviation of Raffinose Family Oligosaccharides (RFOs) of seed- and sprout-flours of soybean [Glycine max (L.) Merr.] - a commercial aspect. Int. Food Res. J. 26, 105-116.

Reddy, N. R., and Salunkhe, D. K. (1980). Changes in oligosaccharides during germination and cooking of black gram and fermentation of black gram/rice blend. Cereal Chem. 57, 356-360.

Redekar, N. R., Glover, N. M., Biyashev, R. M., Ha, B.-K., Raboy, V., and Maroof, M. A. S. (2020). Genetic interactions regulating seed phytate and oligosaccharides in soybean (Glycine max L.). PLoS One 15:e0235120. doi: 10.1371/journal.pone.0235120

Saini, H. S., and Knights, E. J. (1984). Chemical constitution of starch and oligosaccharide components of "desi" and "kabuli" chickpea (Cicer arietinum) seed types. J. Agric. Food Chem. 32, 940-944. doi: 10.1021/jf001 $24 \mathrm{a} 059$

Salunkhe, D. K., and Kadam, S. S. (1989). "Legumes in human nutrition: future prospects," in CRC Hand book of World Food Legumes: Nutritional Chemistry, Processing Technology, and Utilization, ed. D. K. Salunkhe (Florida: CRC Press), 311-314.

Sánchez-Mata, M. C., Peñuela-Teruel, M. J., Cámara-Hurtado, M., Díez-Marqués, C., and Torija-Isasa, M. E. (1998). Determination of Mono-, Di-, and Oligosaccharides in Legumes by High-Performance Liquid Chromatography Using an Amino-Bonded Silica Column. J. Agric. Food Chem. 46, 3648-3652. doi: $10.1021 /$ jf980127w

Santarius, K. A., and Milde, H. (1977). Sugar compartmentation in frost-hardy and partially dehardened cabbage leaf cells. Planta 136, 163-166. doi: 10.1007/ BF00396193

Saravitz, D. M., Pharr, D. M., and Carter, T. E. (1987). Galactinol Synthase Activity and Soluble Sugars in Developing Seeds of Four Soybean Genotypes. Plant Physiol. 83, 185-189. doi: 10.1104/pp.83.1.185

Schillinger, J. A., Dierking, E. C., and Bilyeu, K. D. (2013). Soybeans Having High Germination Rates and Ultra-Low Raffinose and Stachyose Content U.S. Patent No 8471 107. Washington, DC: United States Secretary of Agriculture.

Schröder, C., Janzer, V.-A., Schirrmacher, G., Claren, J., and Antranikian, G. (2017). Characterization of two novel heat-active $\alpha$-galactosidases from thermophilic bacteria. Extremophiles 21, 85-94. doi: 10.1007/s00792-016-0885-Z

Sengupta, S., Mukherjee, S., Basak, P., and Majumder, A. L. (2015). Significance of galactinol and raffinose family oligosaccharide synthesis in plants. Front. Plant Sci. 6:656. doi: 10.3389/fpls.2015.00656

Sengupta, S., Mukherjee, S., Goswami, L., Sangma, S., Mukherjee, A., Mukherjee, R., et al. (2012). Manipulation of inositol metabolism for improved plant survival under stress: a "network engineering approach.". J. Plant Biochem. Biotechnol. 21, 15-23. doi: 10.1007/s13562-012-0132-3

Shimosaka, E., and Ozawa, K. (2015). Overexpression of cold-inducible wheat galactinol synthase confers tolerance to chilling stress in transgenic rice. Breed. Sci. 65, 363-371. doi: 10.1270/jsbbs.65.363

Singh, U. (1985). Nutritional quality of chickpea (Cicer arietinum L.): current status and future research needs. Plant Foods Hum. Nutr. 35, 339-351. doi: 10.1007/bf01091779

Singh, U., Kherdekar, M. S., and Jambunathan, R. (1982). Studies on Desi and Kabuli Chickpea (Cicer arietinum L.) Cultivars. The Levels of Amylase Inhibitors, Levels of Oligosaccharides and In Vitro Starch Digestibility. J. Food Sci. 47, 510-512. doi: 10.1111/j.1365-2621.1982.tb10113.x

Skoneczka, J. A., Maroof, M. A. S., Shang, C., and Buss, G. R. (2009). Identification of Candidate Gene Mutation Associated With Low Stachyose Phenotype in Soybean Line PI200508. Crop Sci. 49, 247-255. doi: 10.2135/cropsci2008.07. 0403

Sosulski, F. W., Elkowicz, L., and Reichert, R. D. (1982). Oligosaccharides in Eleven Legumes and Their Air-Classified Protein and Starch Fractions. J. Food Sci. 47, 498-502. doi: 10.1111/j.1365-2621.1982.tb10111.x
Souframanien, J., Roja, G., and Gopalakrishna, T. (2014). Genetic variation in raffinose family oligosaccharides and sucrose content in blackgram [Vigna mungo L. (Hepper)]. J. Food Legum. 27, 37-41.

Stevenson, J. M., Perera, I. Y., Heilmann, I., Persson, S., and Boss, W. F. (2000). Inositol signaling and plant growth. Trends Plant Sci. 5, 252-258. doi: 10.1016/ S1360-1385(00)01652-6

Stoyanova, S., Geuns, J., Hideg, É, and van den Ende, W. (2011). The food additives inulin and stevioside counteract oxidative stress. Int. J. Food Sci. Nutr. 62, 207-214. doi: 10.3109/09637486.2010.523416

Tahir, M., Båga, M., Vandenberg, A., and Chibbar, R. N. (2012). An Assessment of Raffinose Family Oligosaccharides and Sucrose Concentration in Genus Lens. Crop Sci. 52, 1713-1720. doi: 10.2135/cropsci2011.08.0447

Tahir, M., Lindeboom, N., Båga, M., Vandenberg, A., and Chibbar, R. (2011). Composition and correlation between major seed constituents in selected lentil (Lens culinaris Medik) genotypes. Can. J. Plant Sci. 91, 825-835. doi: 10.4141/ cjps2011-010

Taji, T., Ohsumi, C., Iuchi, S., Seki, M., Kasuga, M., Kobayashi, M., et al. (2002). Important roles of drought- and cold-inducible genes for galactinol synthase in stress tolerance in Arabidopsis thaliana. Plant J. 29, 417-426. doi: 10.1046/j. 0960-7412.2001.01227.x

Takagi, R., Sasaki, K., Sasaki, D., Fukuda, I., Tanaka, K., Yoshida, K., et al. (2016). A Single-Batch Fermentation System to Simulate Human Colonic Microbiota for High-Throughput Evaluation of Prebiotics. PLoS One 11:e0160533. doi: 10.1371/journal.pone.0160533

Takakuwa, N., Tamura, M., Ohnishi, M., and Oda, Y. (2007). Sequence analysis of the $\alpha$-galactosidase MEL gene governing the efficient production of ethanol from raffinose-rich molasses in the yeast Lachancea thermotolerans. World J. Microbiol. Biotechnol. 23:587. doi: 10.1007/s11274-006-9257-7

Thole, J. M., and Nielsen, E. (2008). Phosphoinositides in plants: novel functions in membrane trafficking. Curr. Opin. Plant Biol. 11, 620-631. doi: 10.1016/j.pbi. 2008.10.010

Trugo, L. C., Almeida, D. C. F., and Gross, R. (1988). Oligosaccharide contents in the seeds of cultivated lupins. J. Sci. Food Agric. 45, 21-24. doi: 10.1002/jsfa. 2740450104

Trugo, L. C., Farah, A., and Cabral, L. (1995). Oligosaccharide distribution in Brazilian soya bean cultivars. Food Chem. 52, 385-387. doi: 10.1016/03088146(95)93286-Z

Turgeon, R. (1996). Phloem loading and plasmodesmata. Trends Plant Sci. 1, 418-423. doi: 10.1016/S1360-1385(96)10045-5

Valentine, M. F., de Tar, J. R., Mookkan, M., Firman, J. D., and Zhang, Z. J. (2017). Silencing of Soybean Raffinose Synthase Gene Reduced Raffinose Family Oligosaccharides and Increased True Metabolizable Energy of Poultry Feed. Front. Plant Sci. 8:00692. doi: 10.3389/fpls.2017.00692

Valluru, R., and van den Ende, W. (2011). Myo-inositol and beyond - Emerging networks under stress. Plant Sci. 181, 387-400. doi: 10.1016/j.plantsci.2011. 07.009

van Bel, A. J. E. (1993). Strategies of Phloem Loading. Annu. Rev. Plant Physiol. Plant Mol. Biol. 44, 253-281. doi: 10.1146/annurev.pp.44.060193. 001345

Van den Ende, W. (2013). Multifunctional fructans and raffinose family oligosaccharides. Front. Plant Sci. 4:247. doi: 10.3389/fpls.2013.00247

van den Ende, W., and Valluru, R. (2008). Sucrose, sucrosyl oligosaccharides, and oxidative stress: scavenging and salvaging?. J. Exp. Bot. 60, 9-18. doi: 10.1093/ jxb/ern297

van den Ende, W., Peshev, D., and de Gara, L. (2011). Disease prevention by natural antioxidants and prebiotics acting as ROS scavengers in the gastrointestinal tract. Trends Food Sci. Technol. 22, 689-697. doi: 10.1016/j.tifs. 2011.07.005

Vanhaecke, M., Dyubankova, N., Lescrinier, E., and Van Den Ende, W. (2010). Metabolism of galactosyl-oligosaccharides in Stellaria media - Discovery of stellariose synthase, a novel type of galactosyltransferase. Phytochemistry 71, 1095-1103. doi: 10.1016/j.phytochem.2010.04.012

Vanhaecke, M., Van Den Ende, W., Lescrinier, E., and Dyubankova, N. (2008). Isolation and characterization of a pentasaccharide from Stellaria media. J. Nat. Prod. 71, 1833-1836. doi: 10.1021/np800274k

Vanhaecke, M., Van den Ende, W., Van Laere, A., Herdewijn, P., and Lescrinier, E. (2006). Complete NMR characterization of lychnose from Stellaria media (L.) Vill. Carbohydr. Res. 341, 2744-2750. doi: 10.1016/j.carres.2006.09.001 
Vidal-Valverde, C., Frías, J., and Valverde, S. (1993). Changes in the carbohydrate composition of legumes after soaking and cooking. J. Am. Diet. Assoc. 93, 547-550. doi: 10.1016/0002-8223(93)91814-7

Vidal-Valverde, C., Frias, J., Hernández, A., Martín-Alvarez, P. J., Sierra, I., Rodríguez, C., et al. (2003). Assessment of nutritional compounds and antinutritional factors in pea (Pisum sativum) seeds. J. Sci. Food Agric. 83, 298-306. doi: 10.1002/jsfa.1309

Vidal-Valverde, C., Frias, J., Sotomayor, C., Diaz-Pollan, C., Fernandez, M., and Urbano, G. (1998). Nutrients and antinutritional factors in faba beans as affected by processing. Z. Lebensm. Unters. Forsch. A 207, 140-145. doi: 10.1007/ s002170050308

Wang, J., Yang, X., Yang, Y., Liu, Y., Piao, X., and Cao, Y. (2020). Characterization of a protease-resistant $\alpha$-galactosidase from Aspergillus oryzae $\mathrm{YZ1}$ and its application in hydrolysis of raffinose family oligosaccharides from soymilk. Int. J. Biol. Macromol. 158, 708-720. doi: 10.1016/j.ijbiomac.2020.04.256

Wang, N., and Daun, J. (2006). Effects of variety and crude protein content on nutrients and anti-nutrients in lentils. Food Chem. 95, 493-502. doi: 10.1016/j. foodchem.2005.02.001

Wang, Z., Zhu, Y., Wang, L., Liu, X., Liu, Y., Phillips, J., et al. (2009). A WRKY transcription factor participates in dehydration tolerance in Boea hygrometrica by binding to the W-box elements of the galactinol synthase (BhGolS1) promoter. Planta 230, 1155-1166. doi: 10.1007/s00425-009-1014-3

Watanabe, H., Sonoyama, K., Watanabe, J., Yamaguchi, N., Kikuchi, H., Nagura, T., et al. (2004). Reduction of allergic airway eosinophilia by dietary raffinose in Brown Norway rats. Br. J. Nutr. 92, 247-255. doi: 10.1079/BJN200 41179

Xiaoli, X., Liyi, Y., Shuang, H., Wei, L., Yi, S., Hao, M., et al. (2008). Determination of oligosaccharide contents in 19 cultivars of chickpea (Cicer arietinum L) seeds by high performance liquid chromatography. Food Chem. 111, 215-219. doi: 10.1016/j.foodchem.2008.03.039

Xu, G., Xing, W., Li, T., Ma, Z., Liu, C., Jiang, N., et al. (2018). Effects of dietary raffinose on growth, non-specific immunity, intestinal morphology and microbiome of juvenile hybrid sturgeon (Acipenser baeri Brandt $o \times \mathrm{A}$. schrenckii Brandt $\sigma^{7}$ ). Fish Shellfish Immunol. 72, 237-246. doi: 10.1016/j.fsi. 2017.11.001

Xu, W., Yu, S., Liu, Q., Zhang, T., Jiang, B., and Mu, W. (2017). Enzymatic Production of Melibiose from Raffinose by the Levansucrase from Leuconostoc mesenteroides B-512 FMC. J. Agric. Food Chem. 65, 3910-3918. doi: 10.1021/ acs.jafc.7b01265

Xue, C., Tada, Y., Dong, X., and Heitman, J. (2007). The Human Fungal Pathogen Cryptococcus Can Complete Its Sexual Cycle during a Pathogenic Association with Plants. Cell Host Microbe 1, 263-273. doi: 10.1016/j.chom.2007. 05.005
Yang, J., Ni, K., Wei, D., and Ren, Y. (2015). One-step purification and immobilization of his-tagged protein via Ni2+-functionalized Fe3O4@polydopamine magnetic nanoparticles. Biotechnol. Bioprocess Eng. 20, 901-907. doi: 10.1007/s12257-015-0136-7

Zartl, B., Silberbauer, K., Loeppert, R., Viernstein, H., Praznik, W., and Mueller, M. (2018). Fermentation of non-digestible raffinose family oligosaccharides and galactomannans by probiotics. Food Funct. 9, 1638-1646. doi: 10.1039/ C7FO01887H

Zhang, R., Zhao, Y., Sun, Y., Lu, X., and Yang, X. (2013). Isolation, Characterization, and Hepatoprotective Effects of the Raffinose Family Oligosaccharides from Rehmannia glutinosa Libosch. J. Agric. Food Chem. 61, 7786-7793. doi: 10.1021/jf4018492

Zhao, R., Zhao, R., Tu, Y., Zhang, X., Deng, L., and Chen, X. (2018). A novel $\alpha$-galactosidase from the thermophilic probiotic Bacillus coagulans with remarkable protease-resistance and high hydrolytic activity. PLoS One 13:e0197067. doi: 10.1371/journal.pone.0197067

Zhao, T.-Y., Corum, J. W. III, Mullen, J., Meeley, R. B., Helentjaris, T., Martin, D., et al. (2006). An alkaline $\alpha$-galactosidase transcript is present in maize seeds and cultured embryo cells, and accumulates during stress. Seed Sci. Res. 16, 107-121. doi: 10.1079/SSR2006243

Zhuo, C., Wang, T., Lu, S., Zhao, Y., Li, X., and Guo, Z. (2013). A cold responsive galactinol synthase gene from Medicago falcata (MfGolS1) is induced by myoinositol and confers multiple tolerances to abiotic stresses. Physiol. Plant. 149, 67-78. doi: 10.1111/ppl.12019

Conflict of Interest: The authors declare that the research was conducted in the absence of any commercial or financial relationships that could be construed as a potential conflict of interest.

Publisher's Note: All claims expressed in this article are solely those of the authors and do not necessarily represent those of their affiliated organizations, or those of the publisher, the editors and the reviewers. Any product that may be evaluated in this article, or claim that may be made by its manufacturer, is not guaranteed or endorsed by the publisher.

Copyright (C) 2022 Elango, Rajendran, Van der Laan, Sebastiar, Raigne, Thaiparambil, El Haddad, Raja, Wang, Ferela, Chiteri, Thudi, Varshney, Chopra, Singh and Singh. This is an open-access article distributed under the terms of the Creative Commons Attribution License (CC BY). The use, distribution or reproduction in other forums is permitted, provided the original author(s) and the copyright owner(s) are credited and that the original publication in this journal is cited, in accordance with accepted academic practice. No use, distribution or reproduction is permitted which does not comply with these terms. 